\title{
Ultimate Strength Analysis of Normal and High Strength Concrete Wall Panels with Varying Opening Configurations
}

\author{
Hong Guan $^{\mathrm{a} *}$, Carlia Cooper ${ }^{\mathrm{b}}$ and Dong-Jun Lee ${ }^{\mathrm{a}}$ \\ ${ }^{a}$ Griffith School of Engineering, Griffith University Gold Coast Campus, Queensland 4222, Australia \\ ${ }^{b}$ Institute for Sustainable Futures, PO Box 123, Broadway, NSW 2007, Australia
}

\begin{abstract}
Currently the wall panel design equations given in the Australian Standard and the American Institute Code offer no guidelines for the inclusion of side restraints or openings. Empirical formulae have been derived based upon limited test data, in which only the length and location of openings are accounted for with a dimensionless parameter, $\alpha_{x}$. In this study the nonlinear Layered Finite Element Method (LFEM) is used to undertake a comparative study to verify the effectiveness of the method in predicting the failure characteristics of seven (7) two-way normal strength concrete walls without and with window and door openings. The ultimate loads, load-deflection responses up to failure, deflected shapes and crack patterns predicted by the LFEM are compared to the experimental observations. The method is then used to conduct three parametric studies investigating the influence of opening size, length and height on the ultimate load and deflection of twenty (20) high strength wall panels acting in both one-way and two-way.
\end{abstract}

Comparisons of the numerical results to established formula for walls with openings validated the accuracy of the LFEM predictions. Results demonstrate that increase in opening size decreases the axial strength ratio to different degrees for one-way and two-way walls. Increasing only the opening length also significantly decreases the axial strength ratio. Increasing only the opening height has little impact on the ultimate load capacity. Walls analysed in two-way action have an increased strength compared to the one-way counterparts due to the provision of side restraints, however, such improved strength becomes small for a

\footnotetext{
${ }^{*}$ Corresponding author. Tel: +61-7-5552-8708; fax: +61-7-5552 8065

E-mail address: $\quad$ H.Guan@griffith.edu.au
} 
large sized opening. Results further confirm that increasing the opening height together with the length has the most critical effect. Hence to ensure safe design, the combined effects of increasing both the height and length of an opening should be incorporated into the ultimate load formula which is proposed in this study. The results of this study have assisted in verifying the LEFM as a reliable and effective technique for determining a relationship between ultimate load capacity and varying opening configurations so that more dependable design aids and accurate formulae can be established.

Key words: Axially loaded concrete wall panel; eccentric load; opening; numerical analysis.

\section{Introduction}

Reinforced concrete wall panels are widely used as load-bearing components within the core of high-rise buildings and in tilt-up construction. Although a considerable amount of research has been carried out to investigate the behaviour of reinforced concrete wall panels, most of this work has examined axially loaded, solid wall panels supported along the top and bottom edges only $[1,2]$. Openings are generally present in load bearing walls for the provision of services, doors and windows. However, previous experimental research on the strength and behaviour of concrete walls with openings is very limited [3-6] with many researchers expressing the need for more test data to verify empirical design methods. Although limited, research on walls with openings has established some significant conclusions. Experimental tests indicated that slender walls containing openings are susceptible to unpredictable failure characteristics due to buckling and excessive cracking around the openings. Thus it is vital that the behaviour of walls with openings is comprehensively understood. This requires an understanding of the influence of opening parameters such as size, location and type on the failure characteristics of load bearing walls so that reliable design aids can be developed and empirical design formulae further verified.

Currently the wall panel design equations given in the Australian Standard AS3600 [7] and the American Institute Code ACI-318 [8] give no guidelines for the inclusion of side restraints or openings. Empirical formulae have been derived based upon limited test data, in which the length and location of openings are accounted for with a dimensionless parameter $\alpha_{x}$.

Saheb and Desayi [5] were the first to establish an adequate amount of test data on walls with 
openings, upon which the parameter $\alpha_{x}$ could be derived. The study involved testing twelve (12) wall panels to failure under a vertical in-plane uniformly distributed load, to determine the effects of the type (door and window) and location of openings on the strength and behaviour of panels in one-way (walls supported at top and bottom only, Figure 1(a)) and two-way action (walls supported on all four sides, Figure 1(b)). Due to the lack of established methods, equations previously proposed for solid wall panels were modified to account for the effect of the openings. The dimensionless parameter $\alpha_{x}$ was established, which takes into consideration the length and location of openings by the following function:

$$
\alpha_{x}=A_{o x} / A_{x}+d_{x} / L
$$

where $A_{o x} / A_{x}$ accounts for the opening size in the horizontal plane, $d_{x} / L$ corresponds to the opening location in the horizontal direction, and $d_{x}$ is the distance between centres of gravity $\left(C_{x}\right.$ and $\left.C\right)$ of the panel with and without an opening, respectively, in the horizontal plane [5] (see Figure 2). It is evident that the parameter $\alpha_{x}$ does not include the opening height or the combined influence of the opening length and height.

More recently Doh and Fragomeni [6] tested eight (8) one-third to one-half scale wall panels with openings and with a slenderness ratio of 30 or 40 . Incorporating their own data and the test results of Saheb and Desayi [5], the previously published empirical formulae [1,2,9] for walls without an opening were extended to allow for openings and $H / t$ up to 40 [6]. Or,

$$
N_{u o}=\left(k_{1}-k_{2} \alpha_{x}\right) N_{u}
$$

where

$$
N_{u}=2.0 f_{c}^{\prime 0.7}\left(t_{w}-1.2 e-2 e_{a}\right)
$$

in which $N_{u o}$ and $N_{u}$ are respectively the ultimate load of two identical wall panels with and without openings; $\dot{f}_{c}$ is the characteristic compressive strength of concrete; $t_{w}$ is the wall thickness; $e$ is the eccentricity of load and $e_{a}$ is the additional eccentricity due to the out-of-plane deflection of the wall during loading (the $P$ - $\delta$ effect); $k_{1}=1.175$ (one-way) $/ 1.004$ (two-way) and $k_{2}=1.188$ (one-way)/0.933 (two-way) are the constants derived from the test data [6] using a calibration process. 
Comparisons of the ultimate load predicted by the newly established formula (Eq. (2)) to the test data of Doh and Fragomeni [6] and Saheb and Desayi [5] indicate that the new prediction formula is accurate but slightly conservative. Although this is the most comprehensive formula for determining the ultimate load of concrete walls with openings, it still accounts for the opening length and location with the parameter $\alpha_{x}$ as given by Eq. (1), in which the opening height is not considered. Thus at this point in time there is a need for more testing and numerical analysis so that the combined influence of the opening height, length and location can be incorporated into the design of load bearing concrete walls.

The finite element method is increasing in popularity as a technique for analysing the ultimate behaviour of structural elements. The nonlinear Layered Finite Element Method (LFEM), developed by Guan and Loo [10] for cracking and punching shear failure analysis of concrete flat plates, has shown to be able to predict the ultimate behaviour of square walls with square openings [11]. With an increased availability of high-powered computers, numerical modelling approaches are able to provide a cost effective and accurate alternative to the experimental investigation of concrete wall panels $[12,13]$. Additionally, the accuracy of the numerical solution is not limited by experimental errors and uncertainties.

The purpose of this study is thus to conduct a numerical analysis of one-way and two-way concrete walls with window and door type openings using the LFEM. The wall panel and the opening(s) are rectangle and square in shape. The accuracy of the LFEM is initially verified through a comparative study based on seven (7) normal strength wall panels in two-way action tested by Saheb and Desayi [5,9]. Once verified, the LFEM can be used with confidence to ascertain the failure characteristics including the ultimate loads, deformed shapes, load-deflection responses and crack patterns of walls with openings. The LFEM is then used as an effective tool to undertake parametric studies of twenty (20) high strength wall panels (in both one-way and two-way action) independent of any experimental investigation. Once the relationship between the opening parameters and the ultimate capacity of load bearing walls is comprehensively understood, an improved design formula can be proposed and design aids be developed. This will ensure the safe and economical design of load-bearing concrete walls with openings. 


\section{Analysis Tool - Nonlinear Layered Finite Element Method (LFEM)}

The use of layered finite elements provides an effective means of analysing the elasto-plastic failure behaviour and geometric non-linearity of planar continuum concrete structures. The LFEM [14] incorporates a layered model in which each finite element is sub-divided into a number of fully bonded layers, each uniform in thickness, and with constant material properties. However different layers may be assigned different thicknesses and materials, which allows for an accurate detection of cracks in each concrete layer, and for the inclusion of reinforcing steel.

In association with the layered approach, eight-node degenerate shell elements (Figure 3(a)) are adopted to simulate the concrete wall panel. Figure 3(b) shows a typical wall element. The Mindlin plate hypothesis is used to derive such an element from three-dimensional elasticity. Two primary assumptions are adopted: (1) lines normal to mid-surface before deformation remain straight but not necessarily normal after deformations, and (2) the stress component normal to the mid-reference plane is constrained (i.e. $\sigma_{z}=0$ ) at the global, element level, as is required for degeneration from a three-dimensional to a shell element. Based on these assumptions, the shell elements are formulated in such a way that each nodal point located on the mid-reference surface has five degrees of freedom viz the in-plane displacements, $u$ and $v$, transverse displacement $w$ and two independent bending rotations about the $x$ and $y$ axes, i.e. $\theta_{y}$ and $\theta_{x}$ respectively.

A three-dimensional stress state is considered in the model. The stresses in each layer are calculated at Gauss points located at its mid-surface and are assumed to be constant over the layer thickness. In the non-linear analysis, the material state at any Gauss point may be elastic, plastic or fractured depending on the incremental loading history. Figure 4 shows the constitutive models for both concrete and steel.

In the elastic stage, concrete is treated as an isotropic material and the constitutive relation in the material coordinate system $\left(x^{\prime} y^{\prime} z\right)$ is expressed as

$$
d\{\boldsymbol{\sigma}\}=\left[\overline{\overline{\boldsymbol{D}}}_{c}\right] d\{\boldsymbol{\varepsilon}\}
$$


where $\left[\overline{\overline{\boldsymbol{D}}}_{c}\right]=\left[\begin{array}{ccccccc}K+\frac{4}{3} G & K-\frac{2}{3} G & K-\frac{2}{3} G & 0 & 0 & 0 \\ & K+\frac{4}{3} G & K-\frac{2}{3} G & 0 & 0 & 0 \\ & & K+\frac{4}{3} G & 0 & 0 & 0 \\ & & & G & 0 & 0 \\ & & & & & & \\ & & & & & & 0\end{array}\right]$

in which the bulk and shear moduli are respectively $K=E / 3(1-2 v)$ and $G=E / 2(1+v)$. In Eq. (4), the three-dimensional stress and strain components are respectively $\{\boldsymbol{\sigma}\}=\left\{\sigma_{x}, \sigma_{y}, \sigma_{z}, \tau_{x y}, \tau_{x z}, \tau_{y z}\right\}$ and $\{\boldsymbol{\varepsilon}\}=\left\{\varepsilon_{x}, \varepsilon_{y}, \varepsilon_{z}, \gamma_{x y}, \gamma_{x z}, \gamma_{y z}\right\}$. Due to the assumption of $\sigma_{z}=0$, each element has five non-zero stresses $\left(\sigma_{x}, \sigma_{y}, \tau_{x y}, \tau_{x z}, \tau_{y z}\right)$ and five independent strains $\left(\varepsilon_{x}, \varepsilon_{y}, \gamma_{x y}\right.$, $\left.\gamma_{x z}, \gamma_{y z}\right)$. With all the strain components, the principal strains and their corresponding directions can be calculated, based on which the principal stresses and directions can be determined using the appropriate constitutive models for concrete as detailed below in this section.

Concrete failure is identified as a result of either tension cracking or plastic yielding (crushing). An elastic brittle fracture behaviour is assumed for concrete in tension. Cracks are assumed to form in the plane perpendicular to the direction of maximum principal tensile stress upon reaching the specified concrete tensile strength $f_{t}$. Cracking is represented by a set of evenly spaced parallel cracks smeared over the integration zone. Cracked concrete is treated as an orthotropic material and the tension cut-off representation is utilised. The constitutive equation for cracked concrete is given as

$$
d\{\boldsymbol{\sigma}\}=\left[\overline{\overline{\boldsymbol{D}}}_{c r}\right] d\{\boldsymbol{\varepsilon}\}
$$

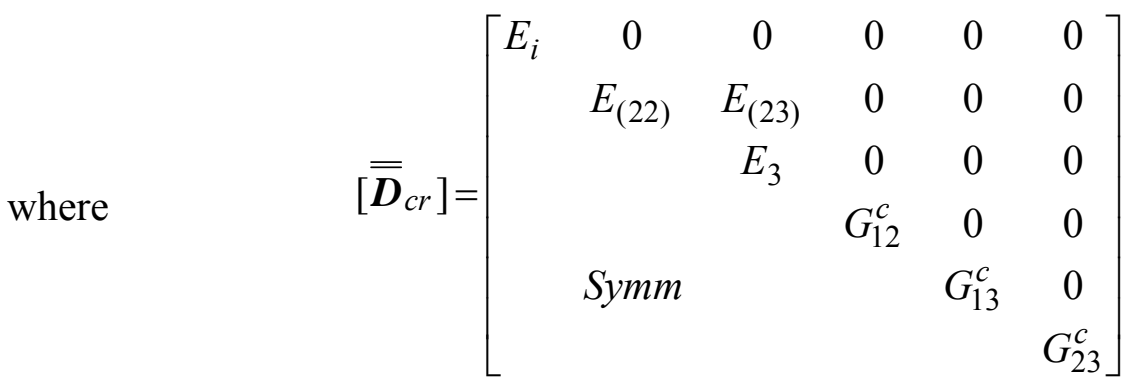


For cracked concrete, the aggregate interlock and dowel action of steel bars contribute, to a different degree in different principal directions, the cracked shear moduli ( $G_{12}^{c}, G_{13}^{c}$ and $G_{23}^{c}$ ) as a function of the current tensile strain [15]. For concrete cracked in one direction, $E_{(22)}=E_{2}$, $E_{(23)}=v \sqrt{E_{2} E_{3}} /\left(1-v-2 v^{2}\right), G_{12}^{c}=G_{13}^{c}=0.25 G\left(1-\varepsilon_{1} / 0.004\right)\left(=0\right.$ if $\left.\varepsilon_{1} \geq 0.004\right)$ and $G_{23}^{c}=(5 / 6) G$. For concrete cracked in two directions, $E_{(22)}=E_{i}$ and $E_{(23)}=0, G_{13}^{c}=0.25 G\left(1-\varepsilon_{1} / 0.004\right) \quad(=0$ if $\left.\varepsilon_{1} \geq 0.004\right), G_{23}^{c}=0.25 G\left(1-\varepsilon_{2} / 0.004\right)\left(=0\right.$ if $\left.\varepsilon_{2} \geq 0.004\right)$ and $G_{12}^{c}=0.5 G_{13}^{c}\left(=0.5 G_{23}^{c}\right.$ if $\left.G_{23}^{c}<G_{13}^{c}\right)$. Due to the bonding interaction between concrete and steel, a gradual release of the concrete stress component normal to the cracked plane is considered to simulate the so-called tension stiffening effect [15]. This is represented in Eq. (7) and Figures 4(a) and (b) by the fictitious modulus of elasticity, $E_{i}=\alpha_{t} f_{t}\left(1-\varepsilon_{t} / \varepsilon_{m}\right) / \varepsilon_{i}$ where $\varepsilon_{t} \leq \varepsilon_{i} \leq \varepsilon_{m}$.Note that Eq. (7) must be transformed from the principal (material) axes to the local $x y z$ coordinate system through the transformation matrix $\left[\boldsymbol{T}_{\varepsilon}\right]$ for strain components. Or,

$$
\left[\boldsymbol{D}_{c r}\right]=\left[\boldsymbol{T}_{\varepsilon^{\prime}}\right]^{T}\left[\overline{\overline{\boldsymbol{D}}}_{c r}\right]\left[\boldsymbol{T}_{\varepsilon^{\prime}}\right]
$$

To model any irrecoverable deformation, the strain-hardening plasticity approach is used to model concrete in compression (see Figure 4(a)). When the minimum principal compressive stress exceeds 0.3 times of the concrete compressive strength $f_{c}$, the initial yield surface is reached which is followed by loading and unloading processes leading to increased plastic deformation. Following a study of Hinton and Owen [15], the direction of the plastic strain increment is defined by the flow rule. In addition, the normality of the plastic deformation rate vector to the yield surface is commonly assumed in establishing the stress-strain relationship in the plastic range. The elasto-plastic constitutive equation relating the incremental stress and strain is given as

$$
d\{\boldsymbol{\sigma}\}=\left[\boldsymbol{D}_{e p}\right] d\{\boldsymbol{\varepsilon}\}
$$

where

$$
\left[\boldsymbol{D}_{e p}\right]=\left[\boldsymbol{D}_{c}\right]-\frac{\left[\boldsymbol{D}_{c}\right] \boldsymbol{a} \boldsymbol{a}^{\mathrm{T}}\left[\boldsymbol{D}_{c}\right]^{\mathrm{T}}}{H^{\prime}+\boldsymbol{a}^{\mathrm{T}}\left[\boldsymbol{D}_{c}\right]^{\mathrm{T}} \boldsymbol{a}}
$$

and

$$
\left[\boldsymbol{D}_{c}\right]=\left[\boldsymbol{T}_{\varepsilon^{\prime}}\right]^{\mathrm{T}}\left[\overline{\overline{\boldsymbol{D}}}_{c}\right]\left[\boldsymbol{T}_{\varepsilon^{\prime}}\right]
$$


for coordinate transformation from the principal axes to the local reference axes $x, y$ and $z$. In Eq. (10), $\boldsymbol{a}$ is the flow vector and $H^{\prime}$ is the hardening parameter associated with the expansion of the yield surface. When the ultimate strain $\varepsilon_{u}$ is reached, the crushing type of failure transpires in concrete. The LFEM assumes some but not all strength and rigidity of the material is lost. The material matrix for concrete taking into account the effect of bulk modulus is

$$
\left[\boldsymbol{D}_{\text {crs }}\right]=\left[\begin{array}{cccccc}
K & K & K & 0 & 0 & 0 \\
& K & K & 0 & 0 & 0 \\
& & K & 0 & 0 & 0 \\
& & & 0 & 0 & 0 \\
& S y m m & & & 0 & 0 \\
& & & & & 0
\end{array}\right]
$$

The orthogonal mesh of steel reinforcing bars are modelled as 'smeared' layers of equivalent thickness whereby the volume of the reinforcing bars is averaged over the element length perpendicular to the bar direction. Each 'smeared' steel layer is assumed to have elastic-plastic uniaxial behaviour in the direction of the reinforcing bars (see Figure 4(c)). The constitutive relation for a steel layer is given as

$$
d\{\boldsymbol{\sigma}\}=\left[\overline{\overline{\boldsymbol{D}}}_{s}\right] d\{\boldsymbol{\varepsilon}\}
$$

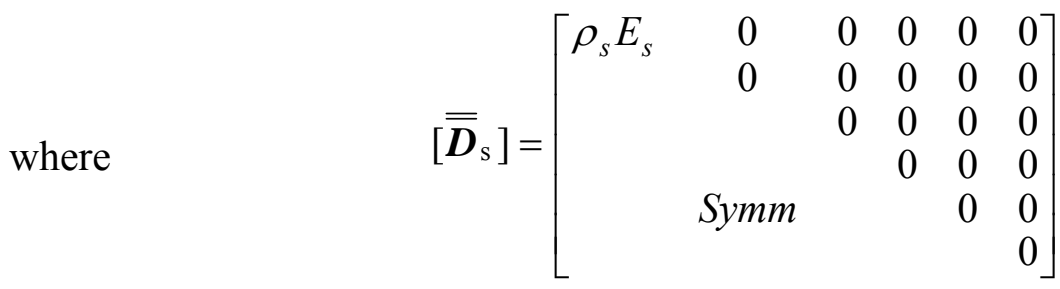

and

$$
\left[\boldsymbol{D}_{s}\right]=\left[\boldsymbol{T}_{\varepsilon^{\prime}}\right]^{T}\left[\overline{\overline{\boldsymbol{D}}}_{s}\right]\left[\boldsymbol{T}_{\varepsilon^{\prime}}\right]
$$

for coordinate transformation from the direction of steel bars to the local coordinate system.

The total material matrix for each element can be determined based on the principal of superposition where the contributions of concrete $\left(n_{c}\right)$ and steel $\left(n_{s}\right)$ layers are added up. Or, 


$$
[\overline{\boldsymbol{D}}]=\sum_{i=1}^{n_{c}}\left[\overline{\boldsymbol{D}}_{c}\right]+\sum_{i=1}^{n_{s}}\left[\boldsymbol{D}_{s}\right]
$$

where $\left[\overline{\boldsymbol{D}}_{c}\right]=\left[\boldsymbol{D}_{c r}\right]$ or $\left[\boldsymbol{D}_{e p}\right]$ or $\left[\boldsymbol{D}_{c r s}\right]$ depending on the actual material condition. The stiffness matrix for the corresponding element can be evaluated using the Gaussian integration technique with the selective integration rule. The structural stiffness matrix is then assembled using the standard procedure. The reliability of the material constitutive model has been demonstrated in various publications $[10,14,16]$.

A total Lagrangian formulation for degenerate shell elements is adopted to deal with the change in structural geometry due to large deformation [15]. The current stress/strain and displacement fields are referred to, respectively, the original geometric configuration and the initial un-deformed position. The incremental and iterative Newton-Raphson method is used to obtain the nonlinear solution due to both material and geometric nonlinearities.

\section{Normal Strength Concrete Wall Panels in Two-Way Action - Comparative Study}

\subsection{The wall models}

Six (6) wall panels tested by Saheb and Desayi [5] with varying window and door opening configurations are analysed in this study. For a more comprehensive comparison of the LFEM predictions and the experimental results, a solid panel tested by the same team is also included. Note that all the walls analysed herein are in two-way action.

The geometric and material parameters are identical to those specified for the experimental work. As seen in Figure 5, all of the models are $600 \mathrm{~mm}$ high, $900 \mathrm{~mm}$ long, and $50 \mathrm{~mm}$ thick, with an aspect ratio $(H / L)$, thinness ratio $\left(L / t_{w}\right)$, and slenderness ratio $\left(H / t_{w}\right)$ (see Figure 2$)$ of $0.67,18$, and 12 respectively. The walls with openings are designated WWO-1(P) to WWO-6(P) with the letter P indicating two-way action. The solid panel is designated WAR-1(P). All window openings are of $240 \mathrm{~mm} \times 240 \mathrm{~mm}$ in size and door openings are $210 \mathrm{~mm}$ wide and $420 \mathrm{~mm}$ in height. The dial gauge locations (side of the opening and centre of the column sections) are also indicated in the figure. 
Depending on the geometric configuration, each wall panel is analysed as either a quarter, half or full model. A convergence study is undertaken to determine the most effective element size for the finite element mesh. A series of meshes with an increased number of elements are proposed, with particular emphasise on the refinement around the opening to ensure that the stress concentrations are accurately modelled. The most appropriate mesh in terms of efficiency and accuracy can then be determined when the LFEM predicted ultimate load starts to converge towards the experimental failure load.

A typical wall model detailing the elements and nodes is shown in Figure 6. For each model, every element is sub-divided, in the thickness direction, into eight concrete layers of varying thickness. In the test panels, two layers of steel reinforcement mesh were symmetrically placed on the tension and compression faces for effective resistance to eccentric loading. Each steel mesh consisted of $2.12 \mathrm{~mm}$ and $3 \mathrm{~mm}$ diameter steel bars spaced uniformly in vertical and horizontal directions respectively [5]. For each wall, the spacing of the bars differed depending on the opening arrangement. In the layered model, each layer of steel mesh is modelled as two uniform orthogonal smeared steel layers of equivalent thickness.

For the panels with and without openings, the average cube strength $\left(f_{c u}\right)$ was $35.3 \mathrm{MPa}$ and $22.33 \mathrm{MPa}$ respectively [5]. The characteristic strength was defined as $0.8 f_{c u}$. Therefore the compressive strengths of $28.4 \mathrm{MPa}$ and $17.86 \mathrm{MPa}$ are used in this study for panels with and without openings respectively. The yielding strengths $\left(f_{y}\right)$ of the $2.12 \mathrm{~mm}$ and $3 \mathrm{~mm}$ reinforcing bars are $297 \mathrm{MPa}$ and $985 \mathrm{MPa}$ respectively, and their moduli of elasticity are $2.05 \times 10^{5} \mathrm{MPa}$ and $2.1 \times 10^{5} \mathrm{MPa}$ [5]. The loading is applied as a series of point loads and moments along the top edge of the model to simulate a uniformly distributed load at an eccentricity of $t_{w} / 6$ as adopted in the test [5]. This is presented in Figure 6. Appropriate boundary conditions are applied in the model to simulate the actual restraints used in the experiments [5]: the top and bottom edges of the wall were hinge supported, not allowing any translation in the z-direction and rotation about y-axis. The bottom edge was also restrained in the y-direction. The side edges were restrained by angle sections, therefore not allowing translations in the $\mathrm{x}$ - and z-directions and rotation about $\mathrm{x}$-axis. 


\subsection{Analysis results}

The effectiveness of the LFEM is demonstrated through a comparison with the experimental data and observations in terms of the deformed shapes, the crack patterns, the load-deflection responses as well as the ultimate loads. The deflected shapes for selected walls in two-way action, as demonstrated in Figure 7, are satisfactorily predicted by the LFEM, clearly showing biaxial curvature (see Figure 1(b)).

According to Saheb and Desayi [5], the test panels exhibited cracks propagating from the corners of the openings to the corners of the panel, dividing the panels into triangular portions. It should be noted that the numerically predicted crack patterns indicate the crack directions only (not the crack length and width) at Gauss points, upon the maximum principal tensile stress reaching the specified concrete tensile strength $f_{t}$. As can be seen in Figure 8 for selected wall panels, the cracking behaviour is well predicted by the LFEM, as all the LFEM models show cracks propagating in a similar manner. A larger number of cracks spread over a greater area can be seen in the LFEM results (in tension layer) as compared to the experimental observations (on tension face). This is because in the LFEM a crack is displayed at any Gauss point at which the tensile strength of concrete is exceeded regardless of the length or width of the crack. In the experimental work however, many of the smaller cracks are either not visible to the human eye or merge together forming a larger and more localised crack. Some minor differences between the experimental and numerical results may also be attributed to experimental error and the idealistic nature of the LFEM.

Figure 9 shows the load-lateral deflection curves for selected points corresponding to the dial gauge locations as indicated in Figure 5. Note that the experimental failure loads are also indicated in the figure. Note also that due to symmetry, the LFEM predicts identical load-deflection responses for symmetrical locations, e.g. Points F and A for WWO-1(P) and Points B and D for WWO-4(P). This is however not the case in the experiment due to the prevalence of imperfections and errors associated with materials, test setup and measurements. The experimental observations [5] show the mid-height lateral deflection adjacent to the opening (e.g. Point B in Figure 5) to be greater than that of a mid-point of the column section (between the edges of the opening and wall, e.g. Point $\mathrm{A}$ in Figure 5). This trend is also noticeable in the load-displacement curves for all the seven wall panels, e.g. WWO-1(P), WWO-2(P) and WWO-5(P) as presented in Figures 9. 
The LFEM models undergo varying amounts of plastic deformation (Figure 9). Walls WWO-1(P) and WWO-3(P) undergo considerable plastic deformation before failure occurs. However the other models undergo little plastic deformation which suggests a brittle mode of failure by buckling or instability mechanisms. Experimental observations indicated that failure was mostly due to bending, intensified by buckling of the narrower column sections. Thus the failure mode observed in the experimental investigation is well predicted by the LFEM.

The LFEM ultimate load predictions are satisfactory but slightly overestimated as shown in Table 1 and Figure 10, with comparisons to the experimental failure loads obtained by Saheb and Desayi [5]. The ratios of the LFEM to experimental failure loads vary from 0.99 to 1.22 , with a mean value of 1.09 and a standard deviation of 0.10 . The discrepancies are due to the fact that the LFEM model is idealistic, as the geometry, materials and restraints are assumed to be exactly as specified. This is however not the case in laboratory tests as imperfections often present such as possible dimensional variations, material irregularities, concrete voids, changes in reinforcement location, and the variations in restraint or loading conditions.

The purpose of this comparative study is to establish the LFEM as an effective tool for predicting the failure characteristics of axially loaded concrete walls with openings. The results clearly validate the effectiveness and reliability of the LFEM, and its applicability to walls with openings. The modelling techniques adopted to simulate the geometric, material, restraint and loading conditions of the test panels are also proven to be satisfactory. In general, the LFEM ultimate loads, deflections and crack patterns show close correlation to the experimental observations.

\section{High Strength Concrete Wall Panels in One-Way and Two-Way Action - Parametric Study}

\subsection{The wall models}

In total, twenty (20) wall models are analysed with the LFEM in three parametric studies and the ultimate behaviour of these wall models is examined. The parameters are the size, length and height of an opening. The overall configuration, the material composition as well as the loading and restraint conditions of the wall models are based on the test specimens of Doh and Fragomeni [6]. As presented in Figure 11, all the wall models have a centrally located opening 
either square or rectangle in shape. All models are $1200 \mathrm{~mm}$ in height and $1200 \mathrm{~mm}$ long, with a thickness of $40 \mathrm{~mm}$. This makes a slenderness ratio of 30 .

The first parametric study investigates the influence of varying the opening size (combined effect of the opening height and length), as illustrated in Figure 11(a). The second parametric study (see Figure 11(b)) is to investigate the influence of increasing the opening length (from $300 \mathrm{~mm}$ to $800 \mathrm{~mm}$ ) while maintaining a constant height $(300 \mathrm{~mm})$. The third parametric study (see Figure 11(c)) investigates the effect of increasing the opening height (from $300 \mathrm{~mm}$ to $800 \mathrm{~mm}$ ), whilst the length remains constant as $300 \mathrm{~mm}$. The designations of all the models are also indicated in the figure, where A, L and $\mathrm{H}$ represent the opening size, length and height respectively; OW and TW refer to one-way and two-way action respectively. Note that A-OW3, L-OW3 and H-OW3 are identical models and the same is true for A-TW3, L-TW3 and H-TW3.

Satisfactory results from the comparative study presented in Section 3 confirm the effectiveness of the numerical modelling technique. For the parametric studies, only a quarter of each wall model is analysed due to symmetry. Each wall model is sub-divided, in the thickness direction, into eight concrete layers of varying thickness. One single layer of F41 mesh (consisting of $4 \mathrm{~mm}$ nominal diameter bars spaced at $100 \mathrm{~mm}$ in both horizontal and vertical directions) is modeled centrally by two orthogonal smeared layers of equivalent thickness.

The average cylinder strength $\left(f_{c m}\right)$ is taken as $67 \mathrm{MPa}$. The characteristic strength of concrete in compression $\left(f_{c}\right)$ is assumed to be $0.85 f_{c m}$ which is used in the analysis. The yielding strength of steel $f_{y}$ is taken as $450 \mathrm{MPa}$. Similar to the modeling approach described in Section 3.1 , the uniformly distributed eccentric load at $t_{w} / 6$ is applied as a series of point loads and moments along the top edge of the model. The restraints for the top, bottom and side edges of the model are also identical to those adopted in Section 3.1. For one-way wall models, however, the side edges are free from any restraint. In addition, symmetrical boundary conditions are assigned to nodes on the lines of symmetry.

\subsection{Ultimate load and deflection}

\subsubsection{Parametric study 1 - opening size}

The ultimate load of each wall model is presented by plotting the axial strength ratio against 
the dimensionless size parameter $A_{o} / A$, as shown in Figure 12, where $A_{o}=A_{o x}=A_{o y}$ and $A=A_{x}=A_{y}$ (see Figure 2). $A_{o} / A$ is similar to the parameter $\alpha_{x}$, however since the wall models and openings in this parametric study have unit aspect ratios, the size parameter $A_{o} / A$ also relates to the vertical cross section (see Figure 2). The axial strength ratio is equal to the predicted failure load given by the LFEM $N_{u o}$ divided by the concrete strength $f_{c}^{\prime}$, the length $L$ and thickness $t_{w}$ of the wall panel. The axial strength ratio eliminates the effects of changing panel size and concrete strength on the failure load of the panel. This dimensionless quantity is useful for comparing the behaviour of different wall panels.

As can be seen in Figure 12, the wall strength appears to be inversely proportional to the opening size. The axial strength ratio decreases linearly with opening size, indicated by an $\mathrm{R}^{2}$ value (correlation coefficient) of 0.99 for both one-way and two-way action. The strength of the one-way wall models reduces by $92 \%$ as the opening dimension increases from $25 \%$ to $67 \%$ of the wall dimension. Similarly, for the two-way wall models the strength reduction is $86 \%$ as the opening dimension increases from $25 \%$ to $67 \%$ of the wall dimension. Thus increasing the opening size significantly reduces the ultimate load carrying capacity of axially loaded walls in one-way and two-way action.

As summarized in Table 2, the maximum mid-height lateral deflection adjacent to the opening $\delta_{\max , L F E M}$ decreases as $A_{\delta} / A$ is increased. For the one-way wall models a large reduction in deflection occurs after $A_{O} / A$ increases from 0.5 to 0.67 . Whereas for the two-way models, the reduction in deflection is almost proportional to the increase in opening size. The reduced deflections for large sized openings may be attributable to the dominance of brittle failure mechanism due to buckling rather than bending. Figure 13 shows the deflected shapes of wall models A-OW6 and A-TW3.

\subsubsection{Parametric study 2 - opening length}

The variation in the opening length is represented by the length parameter $L_{o} / L$, where $L_{o}=A_{o x} / t_{w}$ and $L=A_{x} / t_{w}$ (see Figure 2). Thus the length parameter only corresponds to the horizontal cross section of the wall, as does the parameter $\alpha_{x}$. A near ideal linear relationship exists between the axial strength ratio and $L_{o} / L$, verified by the $\mathrm{R}^{2}$ values of 0.98 and 0.99 for one-way and two-way action respectively (see Figure 14). As $L_{o} / L$ increases from 0.25 to 0.67 , the ultimate load 
capacity of the one-way wall models decreases by $72 \%$. Similarly, for two-way action the ultimate capacity decreases by $50 \%$. Thus increasing the length of the opening significantly reduces the ultimate load carrying capacity of axially loaded walls in one-way and two-way action. Table 2 indicates that for the two-way wall models, increasing $L_{o} / L$ appears to have the same influence on the maximum lateral deflections $\delta_{\max , L F E M}$ as increasing $A_{o} / A$. For the one-way models, on the other hand, the deflections vary little with increase in $L_{o} / L$.

\subsubsection{Parametric study 3 - opening height}

The height parameter $H_{o} / H$ is only relevant to the vertical cross-section of the wall, where $H_{o} / H$ corresponds to the ratio of the opening height to that of the wall, i.e. $H_{o}=A_{o y} / t_{w}$ and $H=A_{y} / t_{w}$ (see Figure 2). For one-way and two-way action respectively, the variation of the axial strength ratio against $H_{o} / H$ appears almost perfectly linear, validated by the $\mathrm{R}^{2}$ values of 1 and 0.95 (see Figure 15); the ultimate load capacity is only reduced by $17 \%$ and $14 \%$ as $H_{o} / H$ increases from 0.25 to 0.67 . This suggests that increasing $H_{o} / H$ has little effect on the ultimate load carrying capacity, particularly in relation to the influence of $A_{o} / A$ and $L_{o} / L$. For both restraint conditions, the maximum lateral deflections $\delta_{\max , L F E M}$ of the wall models remain relatively unchanged regardless of the height of the opening. This is presented in Table 2.

\subsection{Verification of ultimate load}

Table 2 also compares the ultimate loads $N_{u o}$ predicted by the LFEM to those due to Eq. (2). Note that all the models have centrally located openings. Hence only the first term of $\alpha_{x}$ (i.e. $\left.A_{o x} / A_{x}\right)$ of Eq. (1) is relevant to this study.

When $A_{\delta} / A$ varies the correlation between the LFEM and Eq. (2) also vary for both one-way and two-way models. The $N_{u o, L F E M} / N_{u o, E q \text {.(2) }}$ ratio is close to unity when $A_{\delta} / A$ is small, but the ratio decreases dramatically as $A_{o} / A$ increases. Note that the parameter $\alpha_{x}$ used in Eq. (2) does not consider the combined effect of increasing the height and length of the opening. The LFEM results, on the other hand, reflect the effects of increasing both the opening height and length, thus a large discrepancy exists in the predictions for models with large sized openings. Note also that Eq. (2) produces identical sets of ultimate load for both variations of $A_{\delta} / A$ and $L_{\delta} / L$, because $L_{o} / L$ is equivalent to $A_{o x} / A_{x}$. For the LFEM prediction, however, the failure mechanisms for 
varying the opening length only are expected to be different from those when the entire opening size varies.

For the one-way models with variation in $L_{o} / L$, the correlation between the two predictions is similar to the case of varying $A_{o} / A$, however the reduction in the $N_{u o, L F E M} / N_{u o, E q .(2)}$ ratio as $L_{o} / L$ increases is much less than that as $A_{o} / A$ increases. For the two-way models, a fairly consistent correlation is achieved between the two ultimate load predictions with the LFEM predicting about $11 \%$ higher than that by Eq. (2).

The LFEM predictions for both the one-way and two-way models are slightly decreased with an increase in $H_{o} / H$. This suggested that the ultimate load is marginally affected by the height parameter. Neglecting the effect of $H_{o} / H$, Eq. (2) results in identical ultimate loads for the one-way and two-way models, respectively. This is a reasonable but crude approximation. The LFEM, on the other hand, more accurately and logically predicts the variations in the ultimate loads. The predictions of both LFEM and Eq. (2) further confirm that the opening height is not as critical as the size and length parameters (see Figures 12, 14, 15).

\subsection{Comparison of axial strength ratio for one-way and two-way models}

As summarised in Figure 16, increasing the opening size $A_{o} / A$ has the most critical impact on the load carrying capacity of axially loaded walls in one-way and two-way action. Increasing only the height of the opening has little influence on the ultimate load capacity of the wall. When acting together, $H_{o} / H$ and $L_{o} / L$ have a critical influence. Independently, the opening length also has a major influence on the ultimate load capacity, and appears to make the greatest contribution to the influence of $A_{o} / A$.

Due to the combined effects of increasing the opening height and length, it is evident that disregard of the opening height could result in an under-design of walls with openings. This is reflected in the empirical formula predictions given in Section 4.3. The empirical formulae established by Saheb and Desayi [5] and Doh and Fragomeni [6] only consider $L_{o} / L$. When $A_{o} / A$ is small, near perfect correlation existed between the predictions by the LFEM and Eq. (2). However when $A_{o} / A$ increases to 0.67 , the $N_{u o, L F E M} / N_{u o, E q \text {.(2) }}$ ratio decreases to 0.20 and 0.31 for one-way and two-way action respectively (see Table 2). 
The three parametric analyses clearly demonstrate the improved strength of the two-way panels due to the provision of side restraints (see Table 2). The relative effects of $A_{o} / A, H_{o} / H$ and $L_{o} / L$ are different for the one-way and two-way walls. As the opening size $A_{o} / A$ increases, the difference between the axial strength ratio of the one-way and two-way wall models decreases (see Figure 12). However, Figures 14 and 15 show that as the opening length or the height is increased, such a difference remains relatively constant. Thus the strength increase gained by the side restraints appears to be offset by the combined effects of increasing the height together with the length of the opening.

\section{The Proposed Ultimate Load Formula}

To ensure safe design, the combined effects of increasing the opening height together with the opening length should be incorporated into the dimensionless opening parameter. Based on the findings of parametric study and the test results of Lee [17], the following ultimate load formula is proposed

$$
N_{u o}=\left(k_{1}-k_{2} \alpha_{x y}\right) N_{u}
$$

where

$$
\alpha_{x y}=\frac{\alpha_{x}+\lambda \alpha_{y}}{1+\lambda}
$$

and

$$
\alpha_{y}=A_{o y} / A_{y}+d_{y} / H
$$

in which $A_{o y} / A_{y}$ accounts for the opening size in the vertical plane, $d_{y} / H$ corresponds to the opening location in the vertical direction, and $d_{y}$ is the distance between centres of gravity $\left(C_{y}\right.$ and $C$ ) of the panel with and without an opening, respectively, in the vertical plane (see Figure 2). As a function of $\alpha_{x}$ and $\alpha_{y}$, the proposed opening parameter $\alpha_{x y}$ is now able to cover the effect of both the opening length and height. In Eq. (18), $\lambda(0 \leq \lambda \leq 1)$ is the weighting ratio indicating the percentage of $\alpha_{y}$ in relation to $\alpha_{x}$. $\lambda$ together with the constants $k_{1}$ and $k_{2}$ can be determined by a standard regression analysis through a calibration process which is presented in Table 3.

In Table 3, the ultimate loads $N_{u o, L F E M}$ due to the LFEM are presented for all the wall models in 
one-way and two-way action. Note that L-OW3/H-OW3 and L-TW3/H-TW3 are not included because they are identical to A-OW3 and A-TW3, respectively. Also presented in the table are the predicted ultimate loads $N_{u, E q \text {.(3) }}$ for identical solid wall counterparts as well as the axial strength capacity reduction ratio $N_{u o, L F E M} / N_{u, E q .(3)}$ due to the existence of an opening. The weighting ratio $\lambda$ is chosen to vary from 0 to 1 at an increment of 0.01 . A regression analysis is carried out to determine the best fit for $N_{u o, L F E M} / N_{u, E q .(3)}$ versus $\alpha_{x y}$ for both one-way and two-way wall models. This is presented in Figure 17. It has been found that $\lambda=0.21$ for one-way and $\lambda=0.40$ for two-way models yield the highest correlation coefficient $\mathrm{R}^{2}$ and the corresponding intersection $\left(k_{1}\right)$ and slope $\left(k_{2}\right)$. They are $k_{1}=1.361$ and $k_{2}=1.952$ for one-way models (with $\mathrm{R}^{2}=0.99$ ), and $k_{1}=1.358$ and $k_{2}=1.795$ for two-way models (with $\mathrm{R}^{2}=0.98$ ). All these values are adopted in the new formula, Eq. (17).

It should be noted that the proposed formula is derived based on the three parametric studies where the average compressive strength $\left(f_{c m}\right)$ is $67 \mathrm{MPa}$ and the wall slenderness ratio $\left(H / t_{w}\right)$ is 30 , together with the test results of Lee [17] where $f_{c m}$ ranges between $32-100 \mathrm{MPa}$ and $H / t_{w}$, between 30-40. This well covers the scope of the existing code of practice AS3600 [7]. Note also that a constant load eccentricity of $t_{w} / 6$ is adopted in this study. Whereas the effect of load eccentricity on the failure loads of wall panels with a constant size of opening has found to be significant [11], it is not a focus of this study where a particular emphasis has been given on the opening size, length and height. In addition, the opening location (eccentricity of opening) and type (door) are also important parameters in improving the applicability of the proposed ultimate load formula. All this will constitute a major component of the further experimental and numerical work which will eventually aid to developing a comprehensive design formula.

\section{Conclusion}

The Layered Finite Element Method (LFEM) has been established as a satisfactory and effective tool for predicting the ultimate strength of concrete walls with openings. The method effectively predicts the failure characteristics observed by Saheb and Desayi $[1,5,9]$ for seven (7) normal strength concrete wall panels with varying opening configurations tested in two-way action. The cracking behaviour is well predicted by the LFEM, with some small differences due to the impression of more spread-over cracks in the LFEM models (not uncommon in any finite element analysis) and larger and more localised cracks in the 
experiment. The ultimate load predictions are satisfactory but slightly overestimated. The LFEM load-displacement response reflects the non-linear behaviour expected for concrete structures and correlates well with the experimental measurements. Discrepancies in the test setup appear to have influenced the perceived accuracy of the LFEM predictions.

The numerical modelling technique is then employed for parametric analyses where the LFEM is effectively used to determine the influence of the opening height, length, and overall size on the ultimate load capacity of high strength concrete walls in one-way and two-way action. The following discussions are derived from the analysis of twenty (20) wall models in three parametric studies using the LFEM.

(1) Increasing the height and length of the opening $A_{o} / A$ in equal proportion significantly decreases the axial strength ratio. Increasing $A_{o} / A$ from 0.25 to 0.67 reduces the load carrying capacity by $92 \%$ for one-way and $86 \%$ for two-way walls.

(2) Increasing only the length of the opening $L_{o} / L$ decreases the axial strength ratio. As $L_{o} / L$ increases from 0.25 to 0.67 , the load capacity of the one-way and two-way walls decreases by $72 \%$ and $50 \%$ respectively. For the wall models in two-way action, the side restraints control the effects associated with increasing the opening length.

(3) Increasing only the height of the opening $H_{o} / H$ has little effect on the ultimate carrying capacity and the deflection. Increasing $H_{\delta} / H$ from 0.25 to 0.67 reduces the load carrying capacity by $17 \%$ for one-way and $14 \%$ for two-way walls.

(4) The response of the ultimate load capacity to the variation in the opening size, height and length is approximately linear.

(5) Walls analysed in two-way action have an increased strength due to the provision of side restraints.

(6) The improved strength gained due to the two-way action becomes small when $A_{o} / A$ is large. The strength increase gained by the side restraints appears to be offset by the combined effects of increasing the height together with the length of an opening.

(7) Compared to the one-way walls, the strength increase in the two-way counterparts due to the provision of side restraints remains relatively constant as the length or the height parameter is increased.

Increasing the opening height together with the opening length has the most critical effect on 
the ultimate load carrying capacity of concrete walls in one-way and two-way action. The design formulae proposed by Saheb and Desayi [5] and Doh and Fragomeni [6] for axially loaded walls with openings account for the opening length and location with the dimensionless parameter $\alpha_{x}$. However $\alpha_{x}$ does not account for the opening height. Comparisons to the formula of Doh and Fragomeni [6] validate the accuracy of the LFEM predictions. To ensure safe design, the combined effects of increasing the opening height together with the opening length are incorporated into the proposed opening parameter $\alpha_{x y}$, Eq. (17). A new ultimate load formula is also proposed for walls with openings and acting in both one-way and two-way. To cover a wider range of practical application of walls with openings, more experimental and numerical work is needed to examine the walls with combined parameters. These include concrete strength, slenderness ratio (up to 50), eccentricity of opening and axial load, as well as opening types (window and door). This will help to improve the applicability of the proposed ultimate load formula and establish more accurate design aids for this important class of concrete structures.

\section{References}

[1] Saheb SM, Desayi P. Ultimate strength of RC wall panels in one-way in-plane action. J Struct Eng ASCE 1989;115(10):2617-30.

[2] Doh JH, Fragomeni S. Evaluation of experimental work on concrete walls in one and two-way action. Aus J Struct Eng 2005;6(1):37-52.

[3] Seddon AE. The strength of concrete walls under axial and eccentric loads. Symposium on Strength of Concrete Structures, Cement and Concrete Association, London, May 1956; 445-486.

[4] Zielinski ZA, Troitsky MS, Christodoulou H. Full-scale bearing strength investigation of thin wall-ribbed reinforced concrete panels. ACI J 1982;79/32(4):313-21.

[5] Saheb SM, Desayi P. Ultimate strength of RC wall panels with openings. J Struct Eng ASCE 1990;116(6):1565-78.

[6] Doh JH, Fragomeni S. Ultimate load formula for reinforced concrete wall panels with openings. Advances in Struct Eng 2006;9(1):103-115.

[7] Standards Association of Australia (AS3600). AS3600-2001: Concrete structures. Sydney, Australia, 2001. 
[8] American Concrete Institute (ACI). Building code requirements for reinforced concrete (ACI 318-05) and commentary - ACI318R-05. Detroit, Michigan, 2005.

[9] Saheb SM, Desayi P. Ultimate strength of R.C. wall panels in two-way in-plane action. J Struct Eng ASCE 1990;116(5):1384-402.

[10] Guan H, Loo YC. Flexural and shear failure analysis of reinforced concrete slabs and flat plates. Adv in Struct Eng 1997;1(1):71-6.

[11] Hallinan P, Guan H. Layered finite element analysis of one-way and two-way concrete walls with openings. Adv in Struct Eng 2007;10(1):55-72.

[12] Ghobarah A, Youssef M. Modelling of reinforced concrete structural walls. Eng Struct 1999;21:912-23.

[13] Thomson ED, Perdomo ME, Picón R, Marante ME, Flórez-López J. Simplified model for damage in squat RC shear walls. Eng Struct 2009;31:2215-23.

[14] Loo YC, Guan H. Cracking and punching shear failure analysis of RC flat plates. J Struct Eng ASCE 1997;123(10):1321-30.

[15] Hinton E, Owen DRJ. Finite Element Software for Plates and Shells, Pineridge Press Limited, Swansea, UK, 1984;1-403.

[16] Guan H, Polak MA. Finite element studies of reinforced concrete slab-edge column connections with openings. Can J Civ Eng 2007;34:1-14.

[17] Lee, DJ. Experimental and Theoretical Studies of Normal and High Strength Concrete Wall Panels with Openings, $\mathrm{PhD}$ Thesis, Griffith University, 2008. 


\section{List of Tables}

Table 1. Comparison of ultimate load $N_{u}$ for comparative study

Table 2. Comparison of ultimate load $N_{u o}$ for parametric study

Table 3. Calibration of constants $k_{1}$ and $k_{2}$

\section{List of Figures}

Figure 1. Bending action of wall panel: (a) One-way; (b) Two-way

Figure 2. Geometry of wall panel with opening

Figure 3. Layered finite element model: (a) Eight-node degenerate shell element; (b) Concrete and steel layers in a typical wall element

Figure 4. Constitutive models for concrete and steel

Figure 5. Wall panels analysed in two-way action (dimensions in $\mathrm{mm}$ )

Figure 6. Typical wall model

Figure 7. Predicted deflected shapes: (a) WAR-1(P); (b) WWO-1(P); (c) WWO-5(P); (d) WWO-6(P)

Figure 8. Predicted and experimental crack patterns: (a) WWO-2(P); (b) WWO-3(P); (c) WWO-5(P)

Figure 9. Predicted and experimental load-deflection responses: (a) WAR-1(P); (b) WWO-1(P); (c) WWO-2(P); (d) WWO-3(P); (e) WWO-4(P); (f) WWO-5(P); (g) WWO-6(P)

Figure 10. Experimental vs LFEM ultimate loads

Figure 11. Model layout for parametric studies (dimensions in mm): (a) Parametric study 1 variation of opening size; (b) Parametric study 2 - variation of opening length; (c) Parametric study 3 - variation of opening height

Figure 12. Axial strength ratio vs $A_{o} / A$

Figure 13. Predicted deflected shapes (quarter model): (a) A-OW6; (b) A-TW3

Figure 14. Axial strength ratio vs $L_{o} / L$

Figure 15. Axial strength ratio vs $H_{o} / H$

Figure 16. Comparison of axial strength ratio for one-way and two-way models: (a) One-way models; (b) Two-way models

Figure 17. Regression analysis for one-way and two-way models 


\section{Notation}

[D] $]$

$\left[\overline{\overline{\boldsymbol{D}}}_{c}\right],\left[\boldsymbol{D}_{c}\right]$

$\left[\overline{\boldsymbol{D}}_{c}\right]$

$\left[\overline{\overline{\boldsymbol{D}}}_{c r}\right],\left[\boldsymbol{D}_{c r}\right]$

[ $\left.\boldsymbol{D}_{c r s}\right]$

[D $\left.\boldsymbol{D}_{e p}\right]$

$\left[\overline{\overline{\boldsymbol{D}}}_{s}\right], \quad\left[\boldsymbol{D}_{s}\right]$

[ $\left.\boldsymbol{T}_{\varepsilon^{\prime}}\right]$

$\{\boldsymbol{\sigma}\},\{\boldsymbol{\varepsilon}\}$

a

$d_{x}, d_{y}$

A, $A_{o}$

$A_{x}, A_{o x}$

$A_{y}, A_{o y}$

$C$

$C_{x}, C_{y}$

$e$

$e_{a}$

$E_{1}, E_{2}, E_{3}$

$E_{i}$

$f_{c}{ }^{\prime}$
$=$ total material constitutive matrix in local coordinate system

$=$ constitutive matrix for concrete in material and local coordinate systems, respectively

$=$ constitutive matrix for concrete at different stage

$=$ constitutive matrix for cracked concrete in material and local coordinate systems, respectively

$=$ constitutive matrix for crushed concrete

$=$ elasto-plastic constitutive matrix

$=$ constitutive matrix for steel in material and local coordinate systems, respectively

$=$ transformation matrix for strain components

$=$ stress and strain components, respectively

$=$ flow vector

$=$ distances between centres of gravity of the panel with and without an opening in the horizontal and vertical planes, respectively

$=$ areas of wall panel and opening, respectively

$=$ horizontal cross sections of wall panel and opening, respectively

$=$ vertical cross sections of wall panel and opening, respectively

$=$ Centre of gravity of the panel without an opening

$=$ Centres of gravity of the panel with an opening in the horizontal and vertical planes, respectively

$=$ eccentricity of axial load

$=$ additional eccentricity due to out-of-plane deflection

$=$ elastic moduli of concrete in principal directions

$=$ fictitious modulus of elasticity

$=$ compressive strength of concrete 


$$
\begin{aligned}
& f_{c m} \\
& =\text { average cylinder strength of concrete } \\
& f_{c u} \\
& =\text { average cube strength of concrete } \\
& f_{t} \\
& f_{y} \\
& =\text { tensile strength of concrete } \\
& =\text { yield strength of steel } \\
& G, G_{12}^{c}, G_{13}^{c}, G_{23}^{c} \\
& =\text { shear and reduced shear moduli of uncracked and cracked } \\
& \text { concrete, respectively } \\
& H^{\prime} \\
& H, H_{o} \\
& \text { K } \\
& k_{1}, k_{2} \\
& L, L_{o} \\
& n_{c}, n_{s} \\
& N_{u}, N_{u o} \\
& t_{w} \\
& u, v, w \\
& x^{\prime}, y^{\prime}, z^{\prime} \\
& x, y, z \\
& \alpha_{x}, \alpha_{y} \\
& \alpha_{x y} \\
& \alpha_{t}, \varepsilon_{m} \\
& \varepsilon_{i} \\
& \varepsilon_{t} \\
& \varepsilon_{1}, \varepsilon_{2} \\
& \varepsilon_{u} \\
& \varepsilon_{x}, \varepsilon_{y}, \varepsilon_{z}, \gamma_{x y}, \gamma_{x z}, \gamma_{y z} \\
& =\text { hardening parameter } \\
& =\text { heights of wall panel and opening, respectively } \\
& =\text { bulk modulus of concrete } \\
& =\text { constants } \\
& =\text { lengths of wall panel and opening, respectively } \\
& =\text { total numbers of concrete and steel layers, respectively } \\
& =\text { ultimate load of wall panels used in comparative and parametric } \\
& \text { studies, respectively } \\
& =\text { thickness of wall panel } \\
& =\text { nodal displacements in the } x \text {-, } y \text { - and } z \text {-directions } \\
& =\text { material coordinate system } \\
& =\text { local coordinate system } \\
& =\text { dimensionless parameters for an opening in the horizontal and } \\
& \text { vertical planes, respectively } \\
& =\text { dimensionless parameter for an opening in both the horizontal } \\
& =\text { strain corresponding to } f_{t} \\
& =\text { principal tensile strains in directions } 1 \text { and } 2 \text {, respectively } \\
& =\text { ultimate compressive strain of concrete } \\
& =\text { normal and shear strains in the } x y z \text { coordinate system }
\end{aligned}
$$




$\begin{array}{ll}\sigma_{x}, \sigma_{y}, \sigma_{z}, \tau_{x y}, \tau_{x z}, \tau_{y z} & =\text { normal and shear stresses in the } x y z \text { coordinate system } \\ \delta_{\text {max }} & =\text { maximum mid-height lateral deflection adjacent to the opening } \\ v & =\text { Poisson's ratio } \\ \rho_{s} & =\text { reinforcement ratio } \\ \theta_{x}, \theta_{y} & =\text { nodal rotations about the } y \text { - and } x \text {-directions, respectively }\end{array}$


Table 1. Comparison of ultimate load $N_{u}$ for comparative study

\begin{tabular}{|c|c|c|c|c|c|c|c|}
\hline $\begin{array}{c}\text { Panel } \\
\text { designation }\end{array}$ & WAR-1(P) & WWO-1(I & VWO-2(F & NWO-3(P & WWO-4(F & VWO-5(P & WWO-6(P) \\
\hline$N_{u, L F E M}(\mathrm{kN})$ & 676.2 & 686 & 588 & 539 & 759.5 & 588 & 514.5 \\
\hline$N_{u, \operatorname{Exp}}(\mathrm{kN})$ & 555.96 & 692.47 & 592.83 & 448.38 & 697.47 & 587.83 & 448.38 \\
\hline \multicolumn{8}{|l|}{$N_{u, E x p}$} \\
\hline & & & & & & Mean & 1.09 \\
\hline & & & & & Standa & deviation & 0.10 \\
\hline
\end{tabular}


Table 2. Comparison of ultimate load $N_{u o}$ for parametric study

\begin{tabular}{|c|c|c|c|c|c|c|}
\hline Parametric study & Wall model & $A_{o} / A$ & $\begin{array}{c}N_{u o, L F E M} \\
(\mathrm{kN})\end{array}$ & $\begin{array}{c}N_{u o, E q .(2)} \\
(\mathrm{kN})\end{array}$ & $\frac{N_{u o, L F E M}}{N_{u o, E q(2)}}$ & $\begin{array}{c}\delta_{\max , L F E M} \\
(\mathrm{~mm})\end{array}$ \\
\hline \multirow{10}{*}{$\begin{array}{c}1 \\
\text { (opening size) }\end{array}$} & A-OW3 & 0.25 & 347.27 & 343.93 & 1.01 & 5.73 \\
\hline & A-OW4.5 & 0.375 & 233.97 & 285.76 & 0.82 & 5.66 \\
\hline & A-OW6 & 0.5 & 126.55 & 227.59 & 0.56 & 5.12 \\
\hline & A-OW8 & 0.667 & 29.43 & 150.03 & 0.20 & 2.16 \\
\hline & A-TW3 & 0.25 & 921.16 & 832.16 & 1.11 & 8.83 \\
\hline & A-TW4.5 & 0.375 & 726.92 & 706.24 & 1.03 & 6.82 \\
\hline & A-TW6 & 0.5 & 481.18 & 580.32 & 0.83 & 5.29 \\
\hline & A-TW8 & 0.667 & 126.55 & 412.43 & 0.31 & 2.03 \\
\hline & & & & Mean & 0.72 & \\
\hline & & & \multicolumn{2}{|c|}{ Standard deviation } & 0.34 & \\
\hline \multicolumn{7}{|c|}{$L_{o} / L$} \\
\hline \multirow{11}{*}{$\begin{array}{c}2 \\
\text { (opening length) }\end{array}$} & L-OW3 & 0.25 & 347.27 & 343.93 & 1.01 & 5.73 \\
\hline & L-OW4.5 & 0.375 & 257.51 & 285.76 & 0.90 & 5.54 \\
\hline & L-OW6 & 0.5 & 170.69 & 227.59 & 0.75 & 3.98 \\
\hline & L-OW8 & 0.667 & 98.59 & 150.03 & 0.66 & 5.33 \\
\hline & L-TW3 & 0.25 & 921.16 & 832.16 & 1.11 & 8.83 \\
\hline & L-TW4.5 & 0.375 & 794.61 & 706.24 & 1.13 & 6.90 \\
\hline & L-TW6 & 0.5 & 641.57 & 580.32 & 1.11 & 6.28 \\
\hline & L-TW8 & 0.667 & 456.17 & 412.43 & 1.11 & 1.38 \\
\hline & & & & Mean & 0.97 & \\
\hline & & & \multicolumn{2}{|c|}{ Standard deviation } & 0.18 & \\
\hline & \multicolumn{2}{|r|}{$H_{o} / H$} & & & & \\
\hline \multirow{10}{*}{$\begin{array}{c}3 \\
\text { (opening height) }\end{array}$} & H-OW3 & 0.25 & 347.27 & 343.93 & 1.01 & 5.73 \\
\hline & H-OW4.5 & 0.375 & 329.62 & 343.93 & 0.96 & 5.77 \\
\hline & H-OW6 & 0.5 & 313.43 & 343.93 & 0.91 & 5.55 \\
\hline & H-OW8 & 0.667 & 289.89 & 343.93 & 0.84 & 5.90 \\
\hline & H-TW3 & 0.25 & 921.16 & 832.16 & 1.11 & 8.83 \\
\hline & H-TW4.5 & 0.375 & 907.92 & 832.16 & 1.09 & 8.68 \\
\hline & H-TW6 & 0.5 & 862.30 & 832.16 & 1.04 & 8.50 \\
\hline & H-TW8 & 0.667 & 788.72 & 832.16 & 0.95 & 8.23 \\
\hline & & & & Mean & 0.99 & \\
\hline & & & Standard & deviation & 0.09 & \\
\hline
\end{tabular}


Table 3. Calibration of constants $k_{1}$ and $k_{2}$

\begin{tabular}{|c|c|c|c|c|c|c|}
\hline Action & $\begin{array}{l}\text { Wall } \\
\text { model }\end{array}$ & $\begin{array}{l}\text { Opening size } \\
(\mathrm{mm} \times \mathrm{mm})\end{array}$ & $\begin{array}{l}N_{\text {uо,LFEM }} \\
(\mathrm{kN})\end{array}$ & $\begin{array}{c}N_{u, E q \cdot(3)} \\
(\mathrm{kN})\end{array}$ & $\frac{N_{u o, L F E M}}{N_{u, E q(3)}}$ & $\begin{array}{c}\alpha_{x y} \\
\text { (when } \lambda=0.21)\end{array}$ \\
\hline \multirow{14}{*}{ One-way } & A-OW3 & $300 \times 300$ & 347.27 & 389.3 & 0.892 & 0.250 \\
\hline & A-OW4.5 & $450 \times 450$ & 233.97 & 389.3 & 0.601 & 0.375 \\
\hline & A-OW6 & $600 \times 600$ & 126.55 & 389.3 & 0.325 & 0.500 \\
\hline & A-OW8 & $800 \times 800$ & 29.43 & 389.3 & 0.076 & 0.667 \\
\hline & L-OW4.5 & $300 \times 450$ & 257.51 & 389.3 & 0.661 & 0.353 \\
\hline & L-OW6 & $300 \times 600$ & 170.69 & 389.3 & 0.439 & 0.457 \\
\hline & L-OW8 & $300 \times 800$ & 98.59 & 389.3 & 0.253 & 0.594 \\
\hline & H-OW4.5 & $450 \times 300$ & 329.62 & 389.3 & 0.847 & 0.272 \\
\hline & H-OW6 & $600 \times 300$ & 313.43 & 389.3 & 0.805 & 0.293 \\
\hline & $\underline{\mathrm{H}-\mathrm{OW} 8}$ & $800 \times 300$ & 289.89 & 389.3 & 0.745 & 0.322 \\
\hline & & & & & $R^{2}$ & 0.99 \\
\hline & & & & & $k_{1}$ & 1.361 \\
\hline & & & & & $k_{2}$ & 1.952 \\
\hline & & & & & & $\begin{array}{c}\alpha_{x y} \\
\text { (when } \lambda=0.40)\end{array}$ \\
\hline \multirow{13}{*}{ Two-way } & A-TW3 & $300 \times 300$ & 921.16 & 1073.0 & 0.859 & 0.250 \\
\hline & A-TW4.5 & $450 \times 450$ & 726.92 & 1073.0 & 0.677 & 0.375 \\
\hline & A-TW6 & $600 \times 600$ & 481.18 & 1073.0 & 0.448 & 0.500 \\
\hline & A-TW8 & $800 \times 800$ & 126.55 & 1073.0 & 0.118 & 0.667 \\
\hline & L-TW4.5 & $300 \times 450$ & 794.61 & 1073.0 & 0.741 & 0.339 \\
\hline & L-TW6 & $300 \times 600$ & 641.57 & 1073.0 & 0.598 & 0.429 \\
\hline & L-TW8 & $300 \times 800$ & 456.17 & 1073.0 & 0.425 & 0.548 \\
\hline & H-TW4.5 & $450 \times 300$ & 907.92 & 1073.0 & 0.846 & 0.286 \\
\hline & H-TW6 & $600 \times 300$ & 862.30 & 1073.0 & 0.804 & 0.321 \\
\hline & H-TW8 & $800 \times 300$ & 788.72 & 1073.0 & 0.735 & 0.369 \\
\hline & & & & & $R^{2}$ & 0.98 \\
\hline & & & & & $k_{1}$ & 1.358 \\
\hline & & & & & $k_{2}$ & 1.795 \\
\hline
\end{tabular}




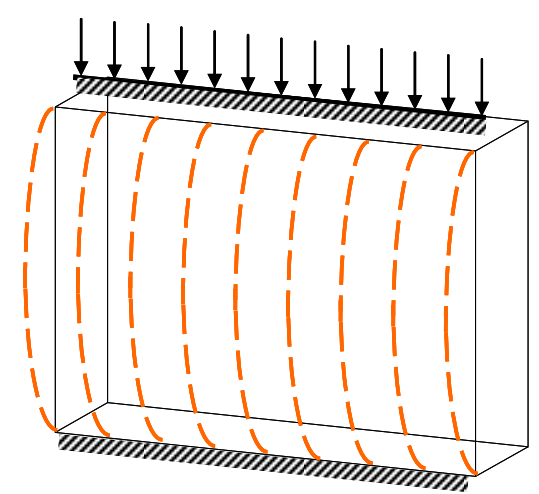

(a) One-way

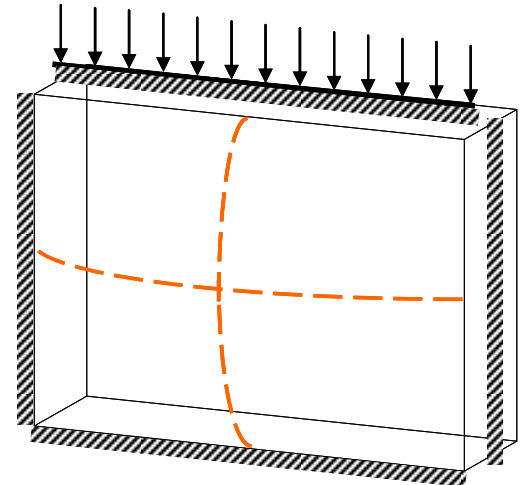

(b) Two-way

Figure 1. Bending action of wall panel 


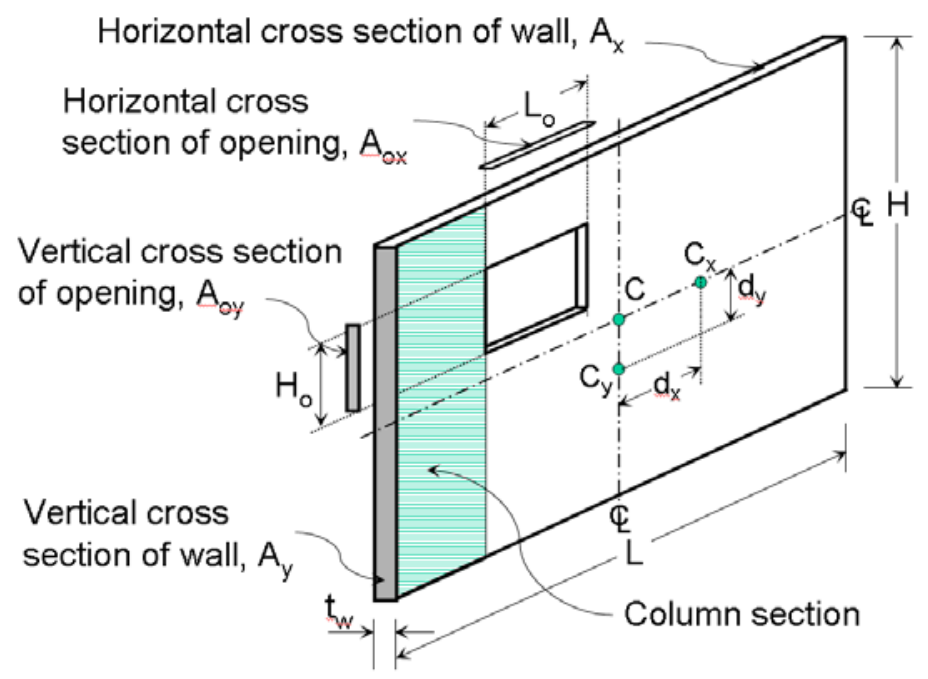

Figure 2. Geometry of wall panel with opening 


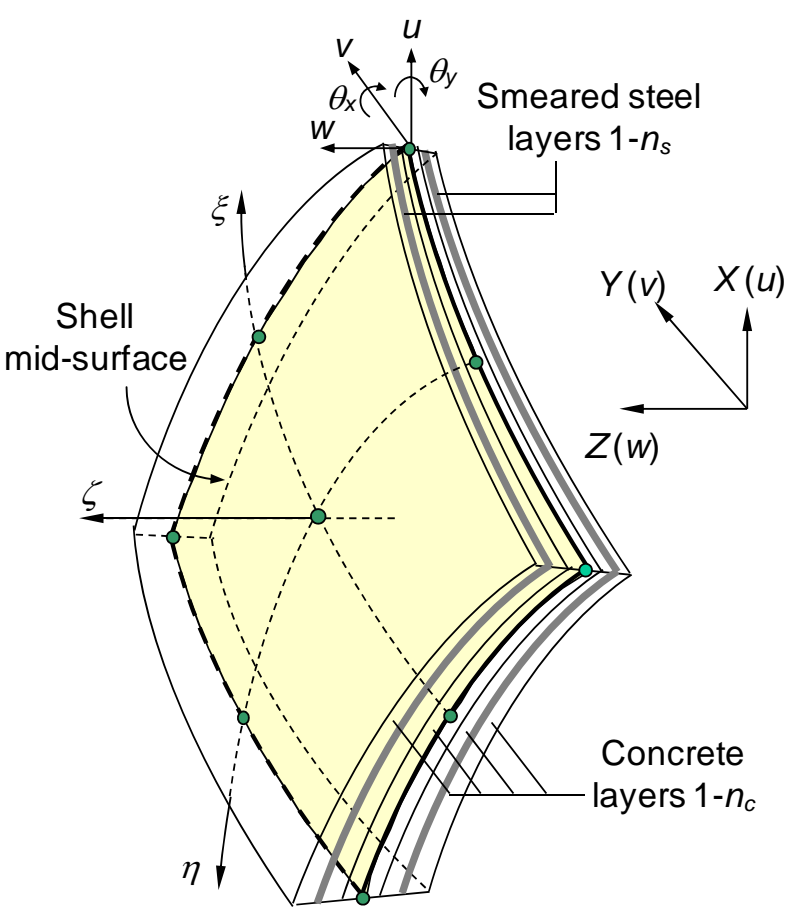

(a) Eight-node degenerate shell element

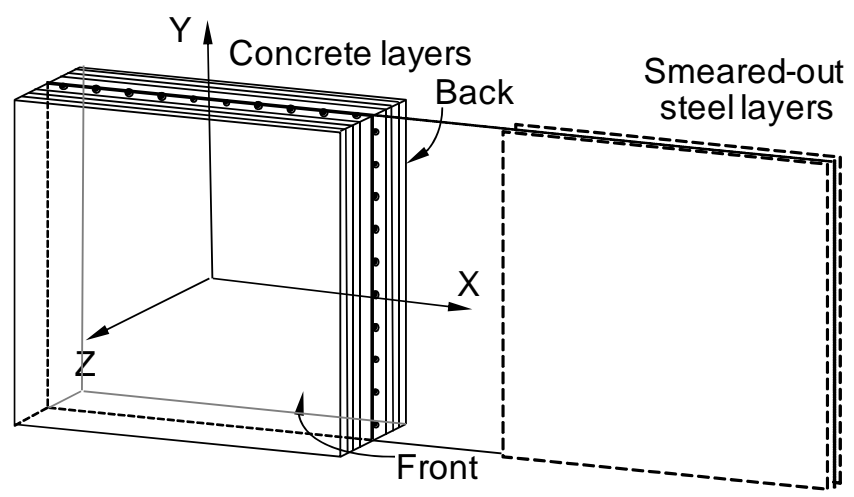

(b) Concrete and steel layers in a typical wall element

Figure 3. Layered finite element model 


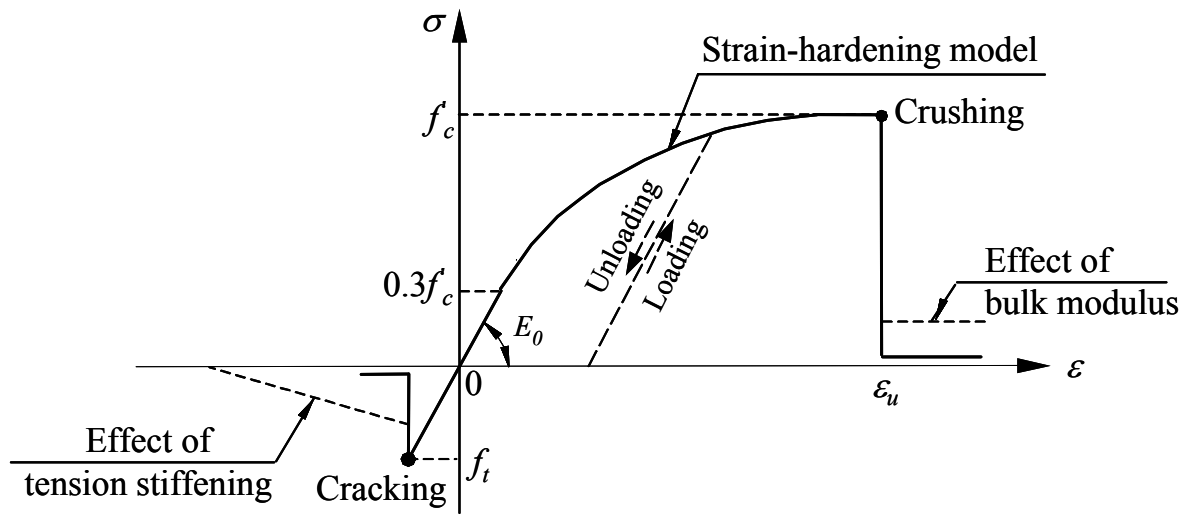

(a) One-dimensional representation for concrete in compression and tension

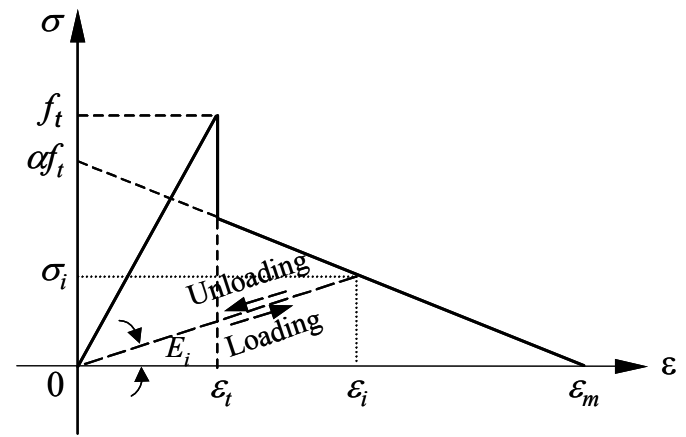

(b) Tension stiffening effect for cracked concrete

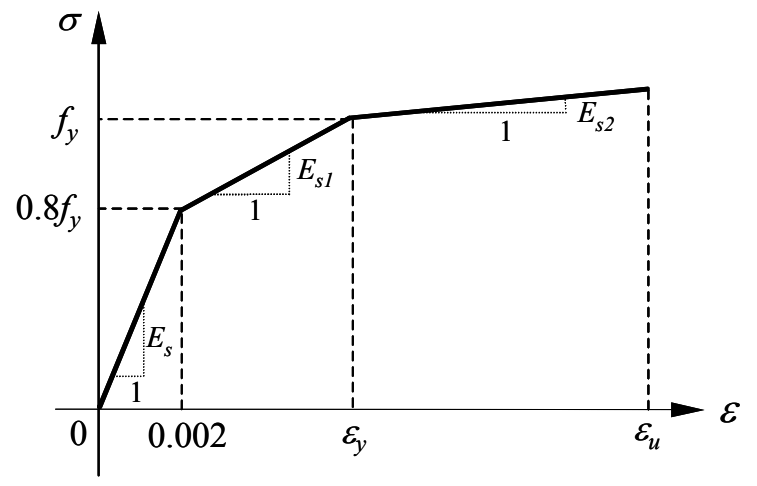

(c) Uniaxial behaviour of steel

Figure 4. Constitutive models for concrete and steel 


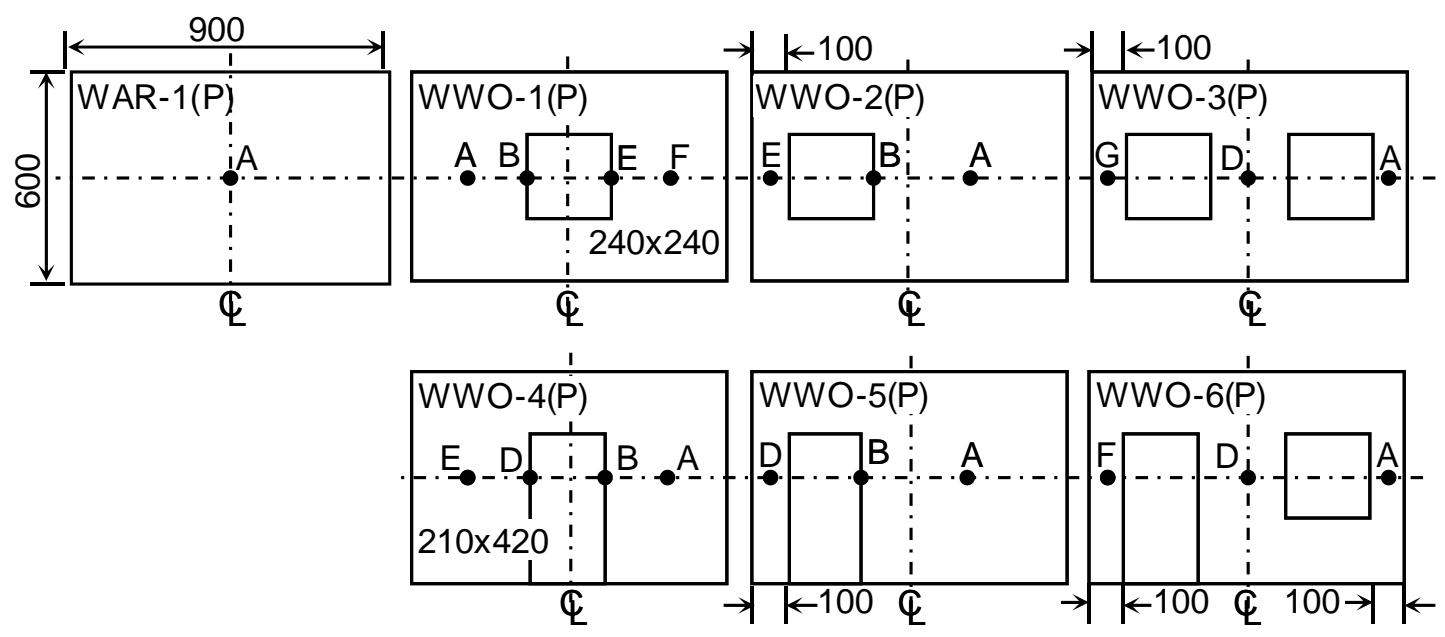

Figure 5. Wall panels analysed in two-way action (dimensions in $\mathrm{mm}$ ) 


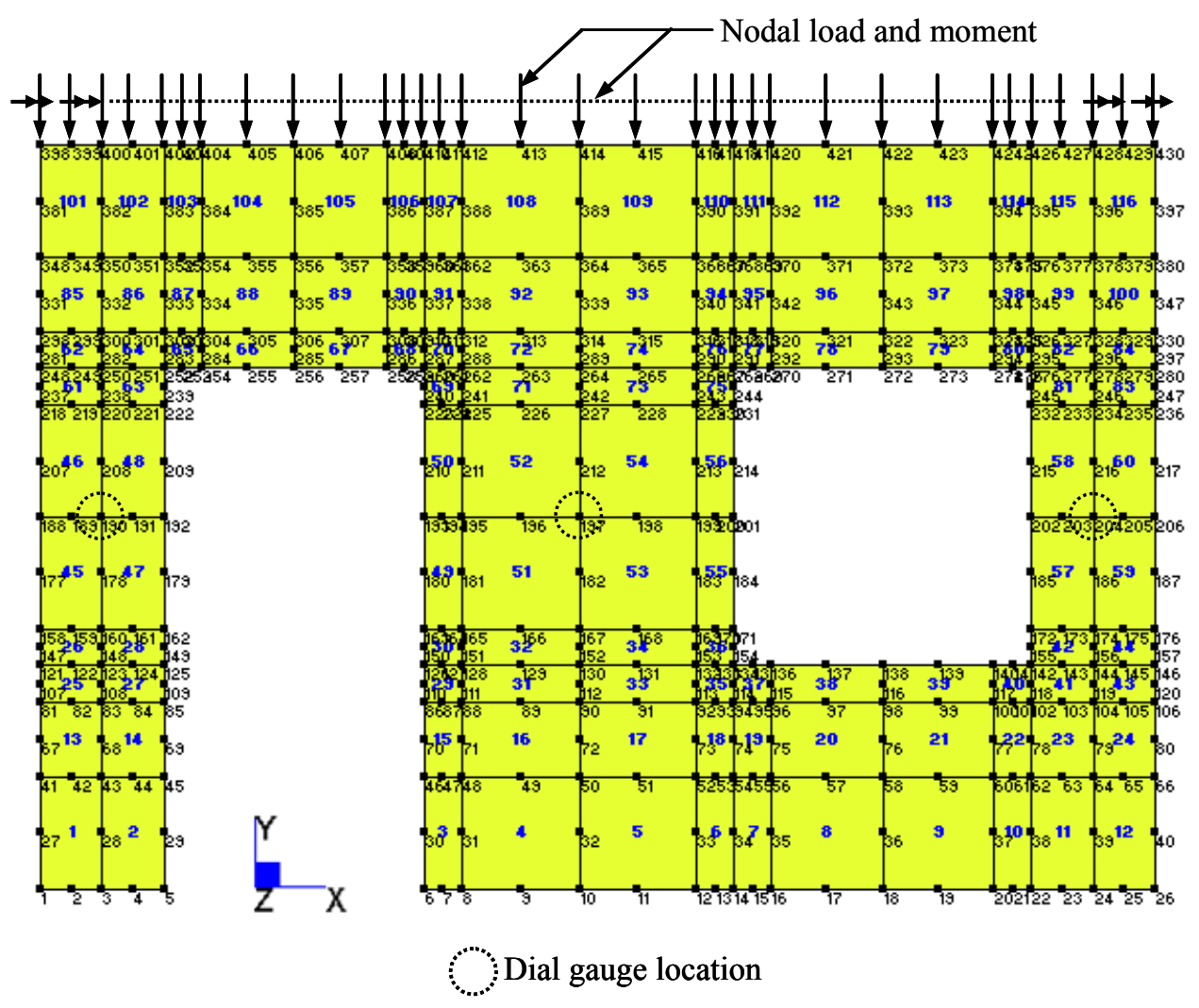

Figure 6. Typical wall model WWO-6(P) 


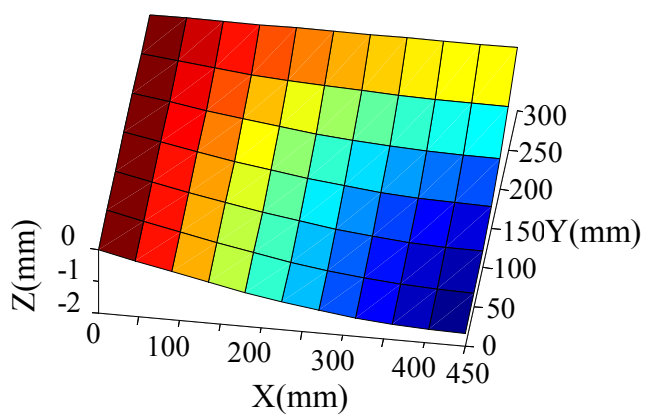

(a) WAR-1(P) (quarter model)

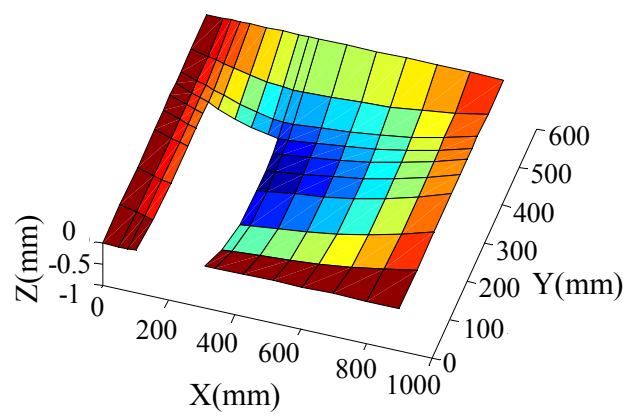

(c) WWO-5(P) (full model)

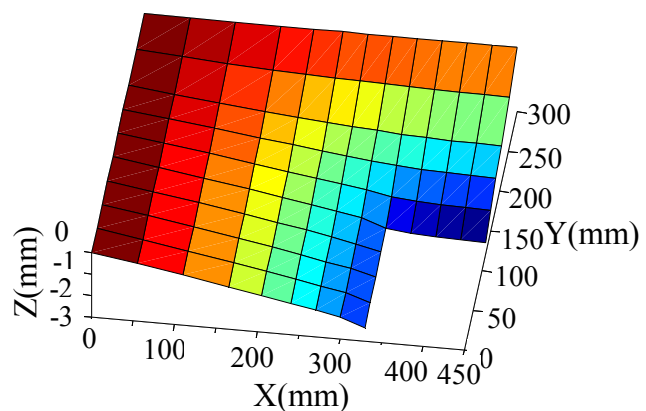

(b) WWO-1(P) (quarter model)

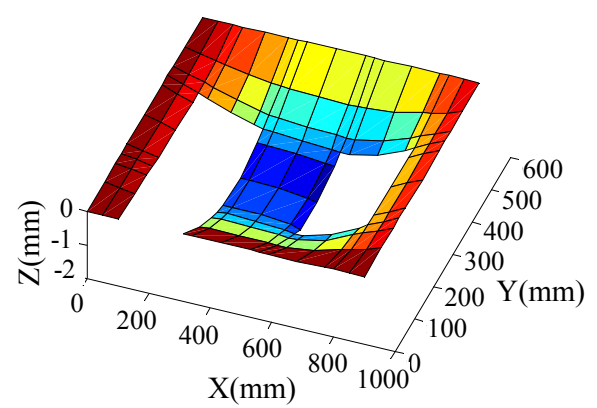

(d) WWO-6(P) (full model)

Figure 7. Predicted deflected shapes 


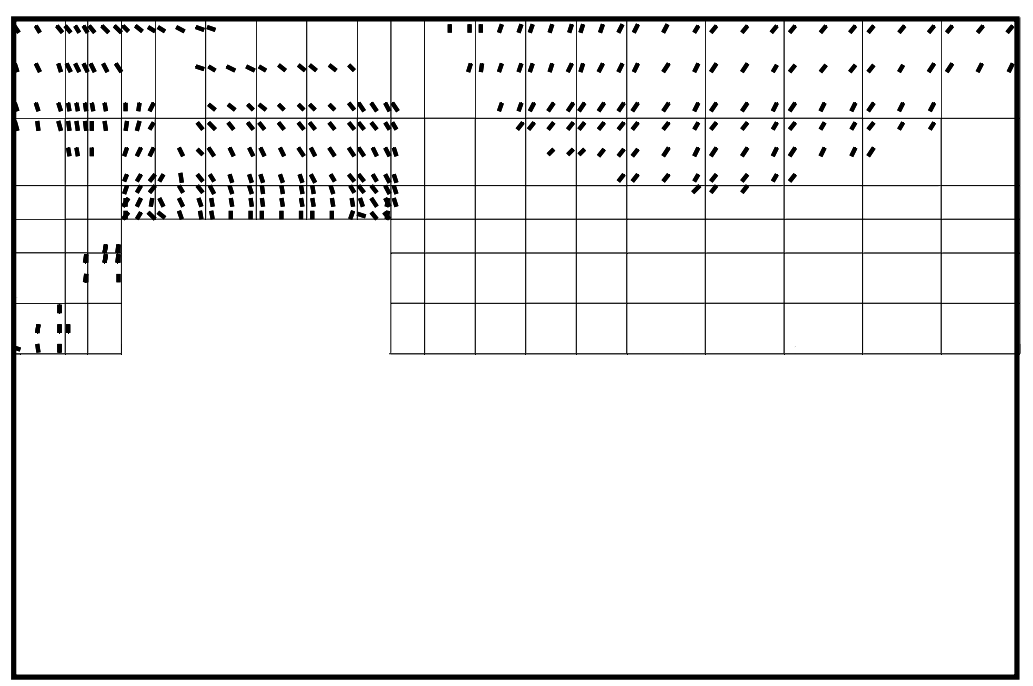

LFEM prediction for half model (tension layer)

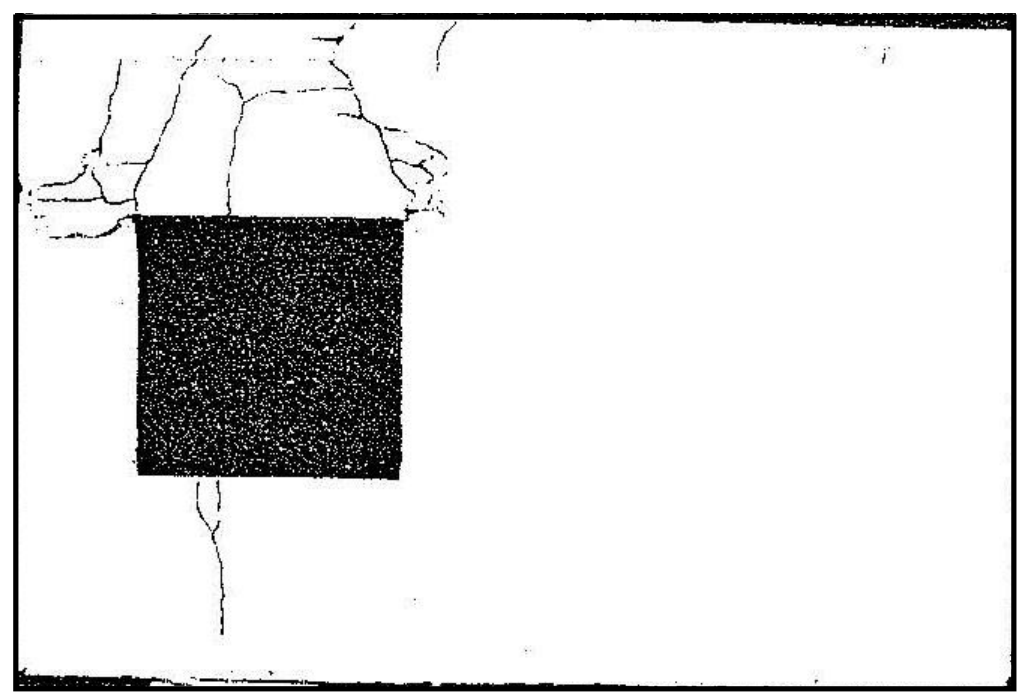

Experimental observation (tension face)

(a) WWO-2(P)

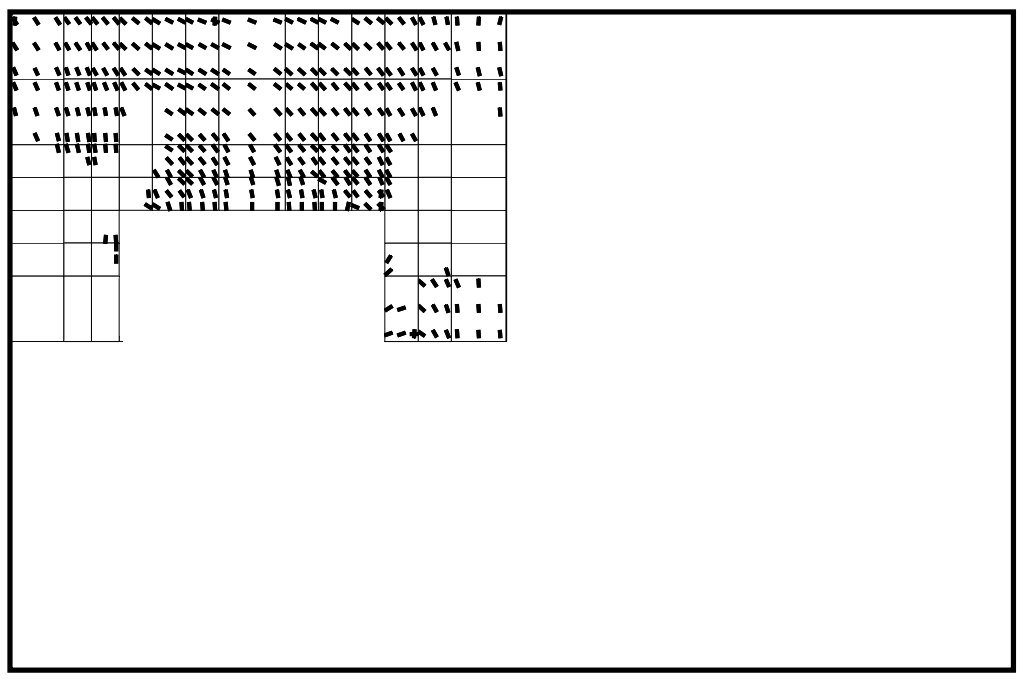


LFEM prediction for quarter model (tension layer)

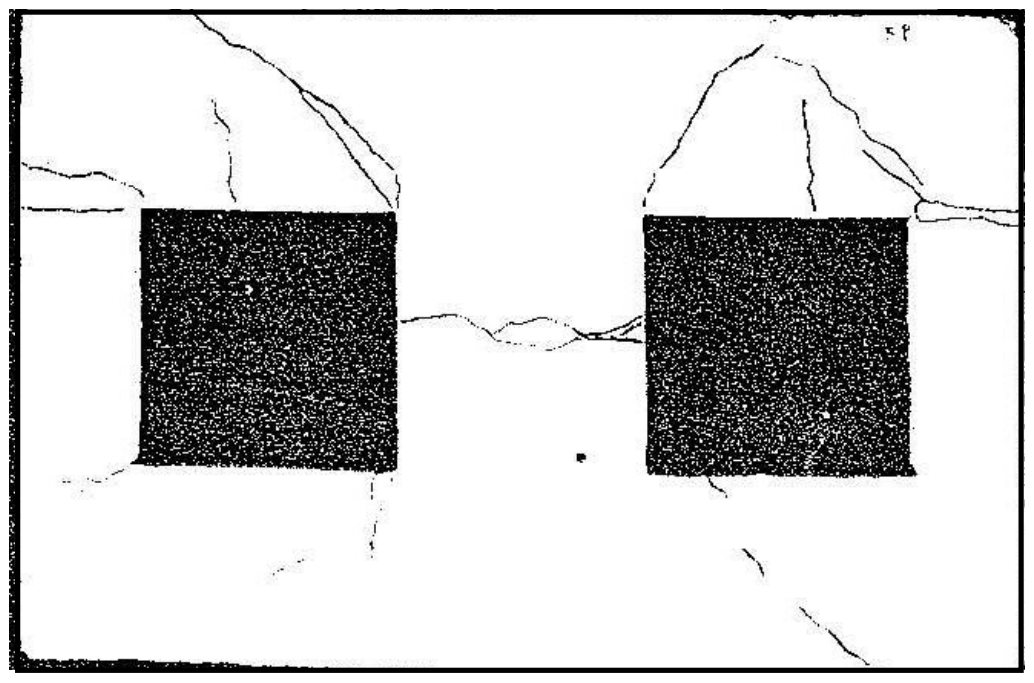

Experimental observation (tension face)

(b) WWO-3(P)

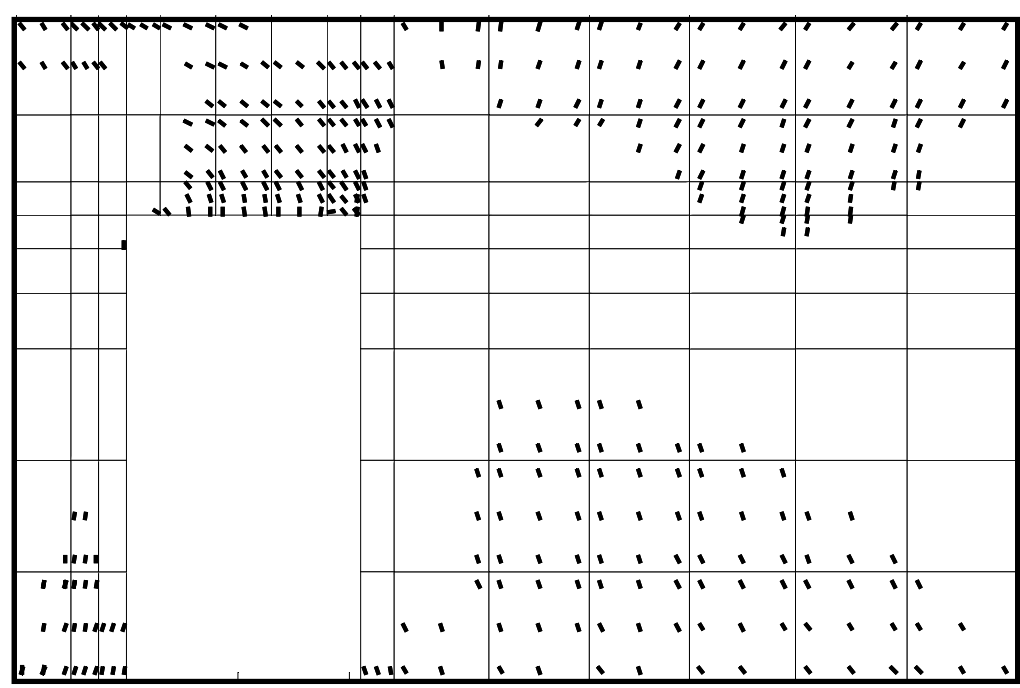

LFEM prediction (tension layer) 


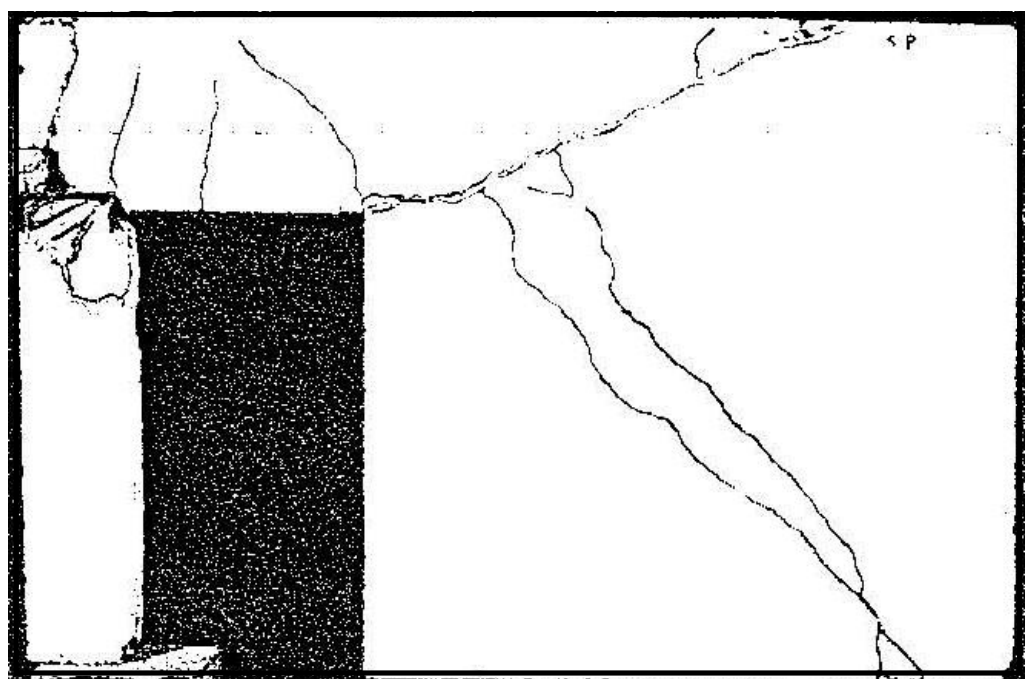

Experimental observation (tension face)

(c) WWO-5(P)

Figure 8. Predicted and experimental crack patterns 


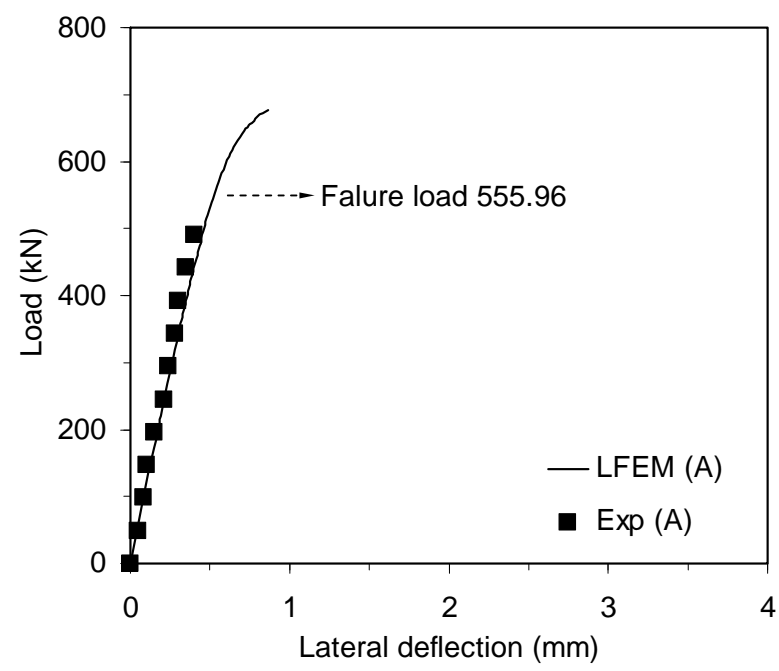

(a) WAR-1(P)

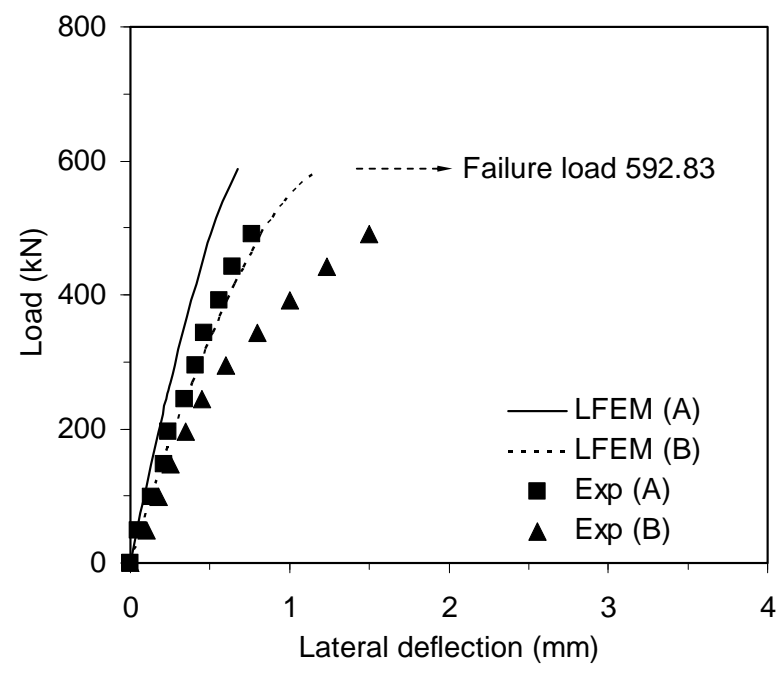

(c) WWO-2(P)

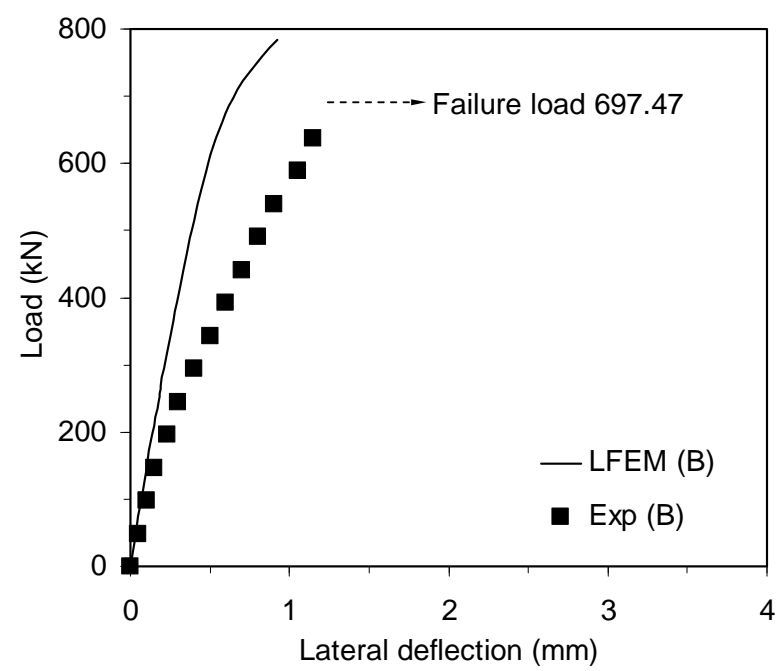

(e) WWO-4(P)

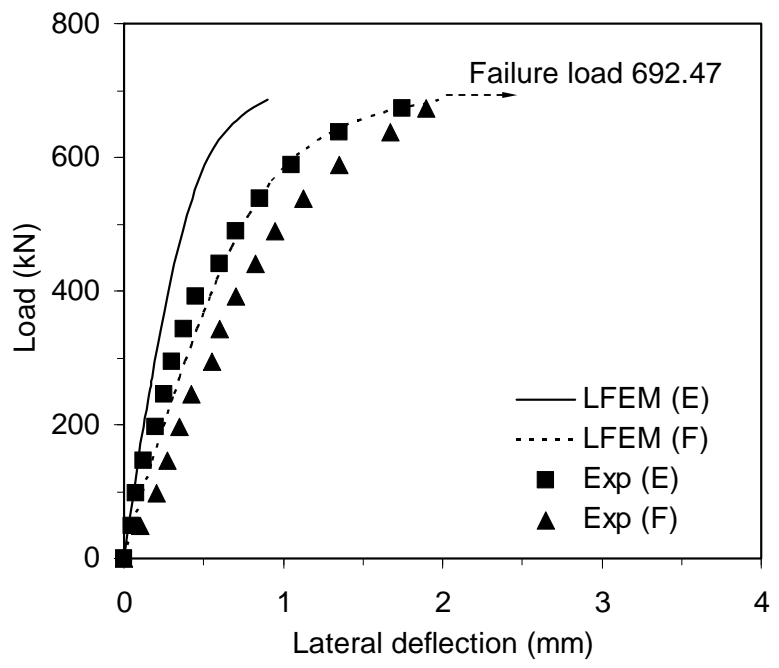

(b) WWO-1(P)

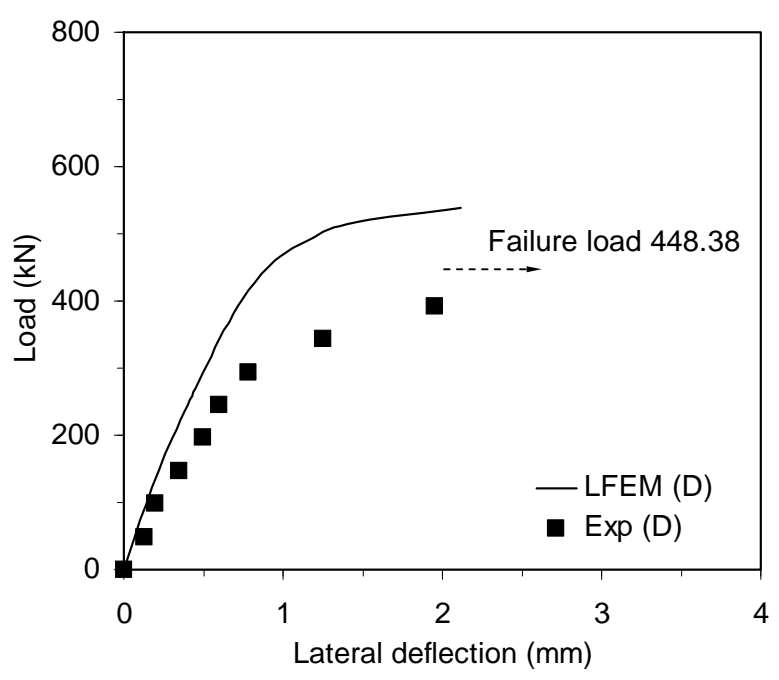

(d) WWO-3(P)

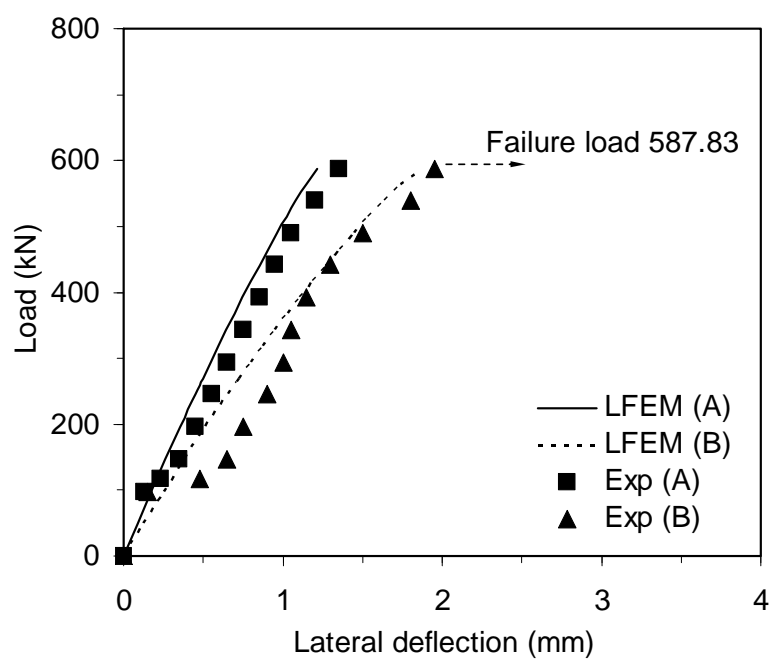

(f) WWO-5(P) 


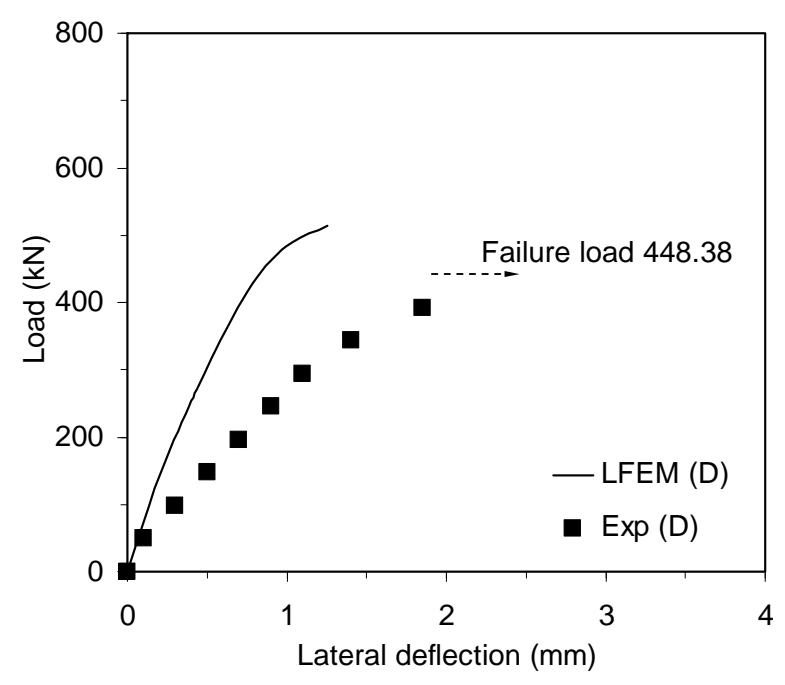

(g) WWO-6(P)

Figure 9. Predicted and experimental load-deflection responses 


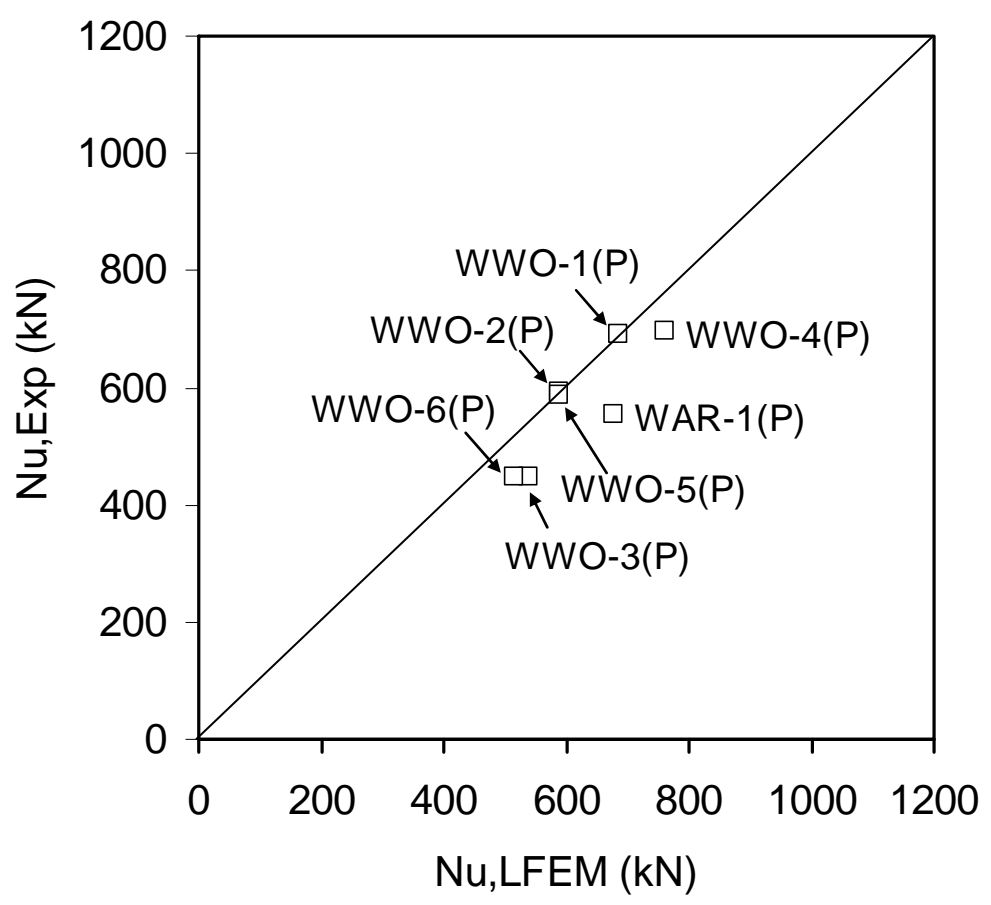

Figure 10. Experimental vs LFEM ultimate loads 


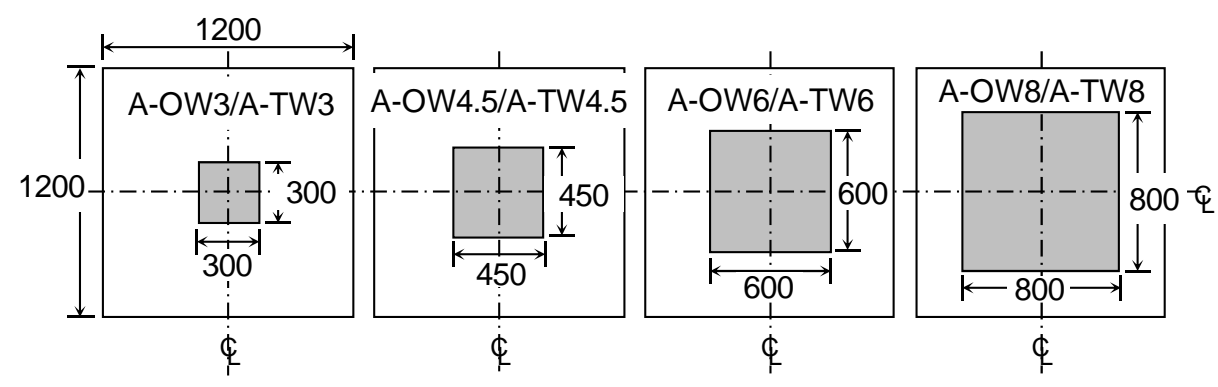

(a) Parametric study 1 - variation of opening size

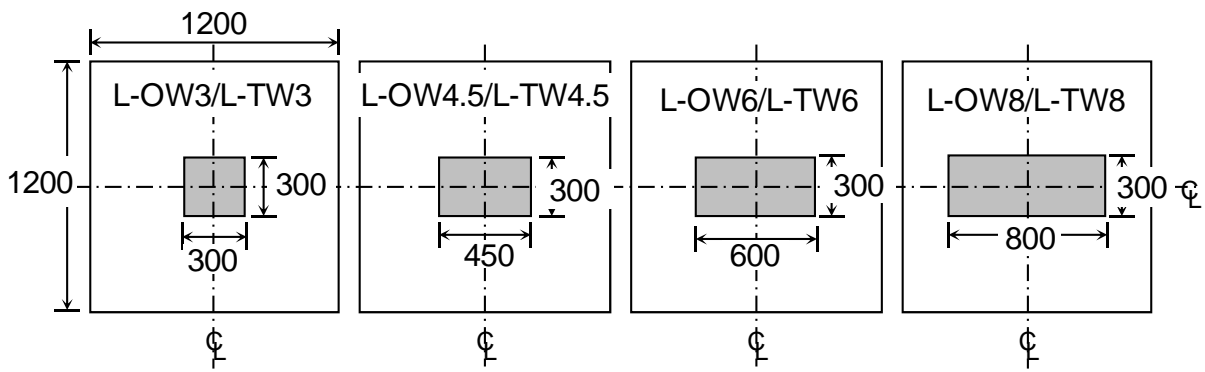

(b) Parametric study 2 - variation of opening length

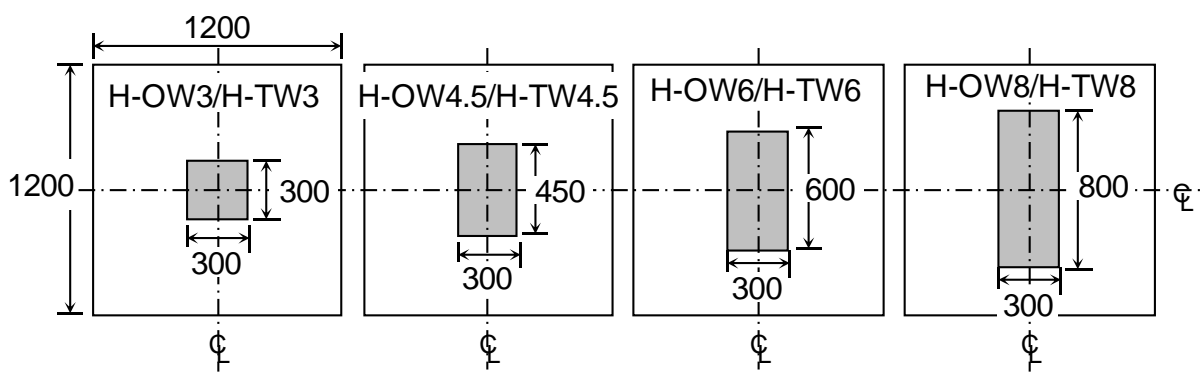

(c) Parametric study 3 - variation of opening height

Figure 11. Model layout for parametric studies (dimensions in $\mathrm{mm}$ ) 


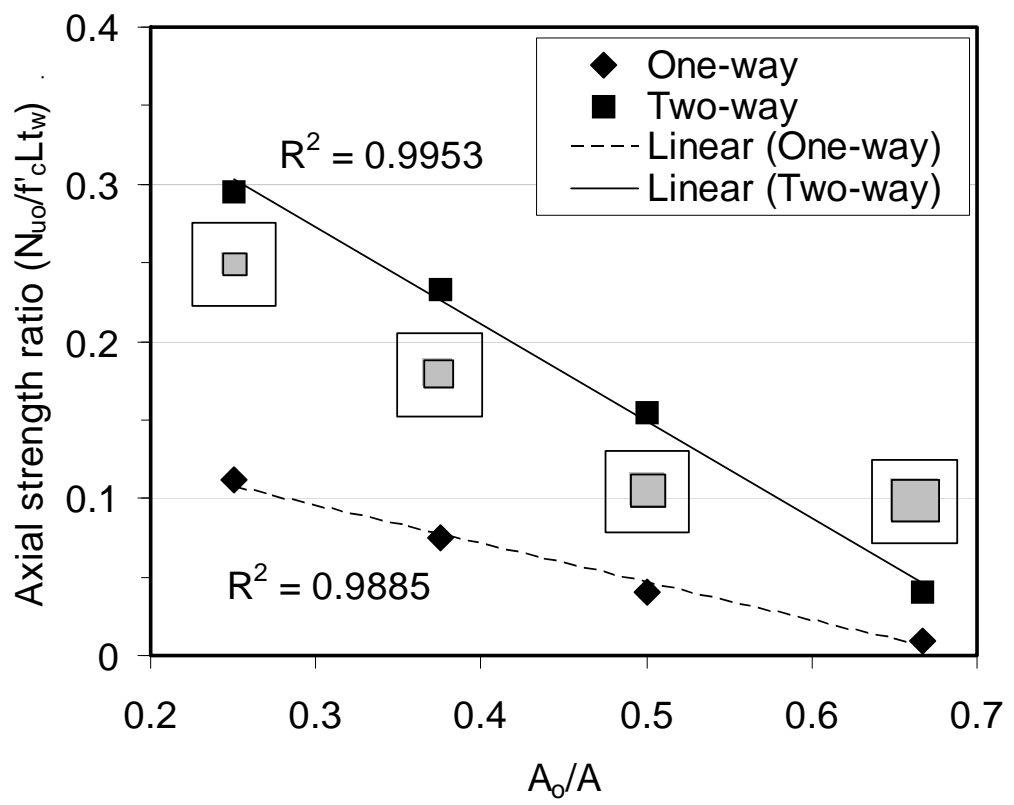

Figure 12. Axial strength ratio vs $A_{o} / A$ 


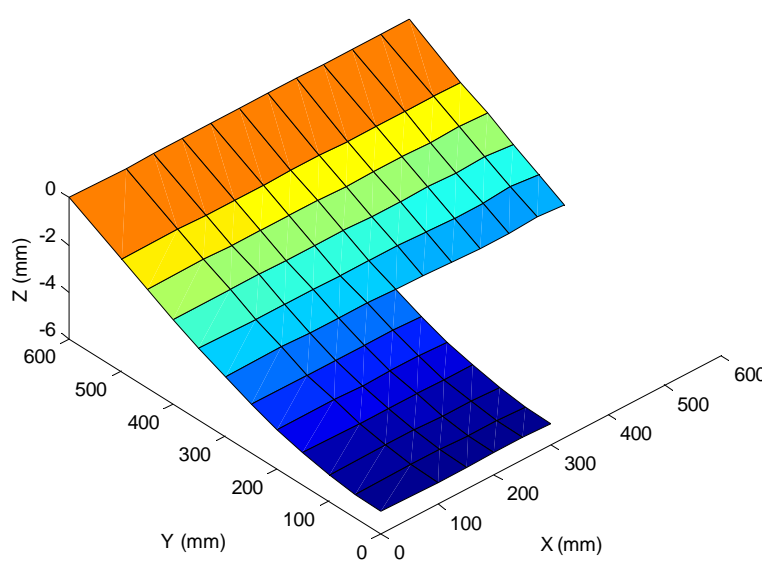

(a) A-OW6

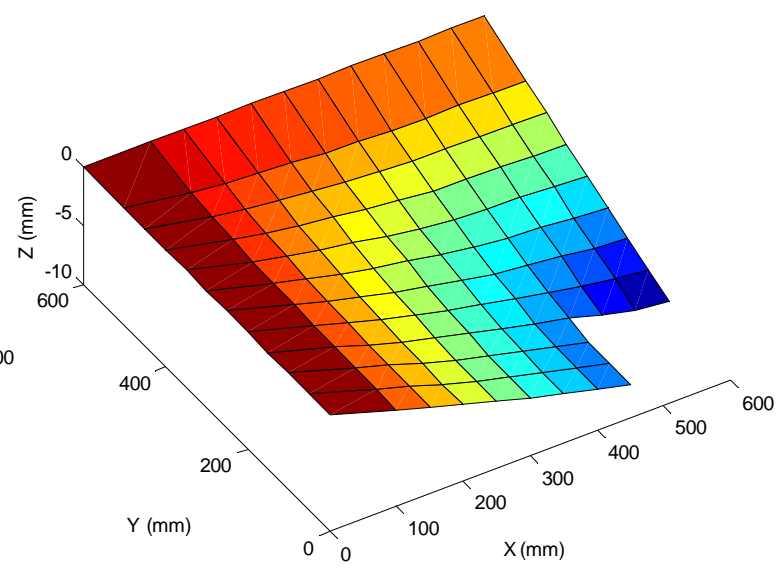

(b) A-TW3

Figure 13. Predicted deflected shapes (quarter model) 


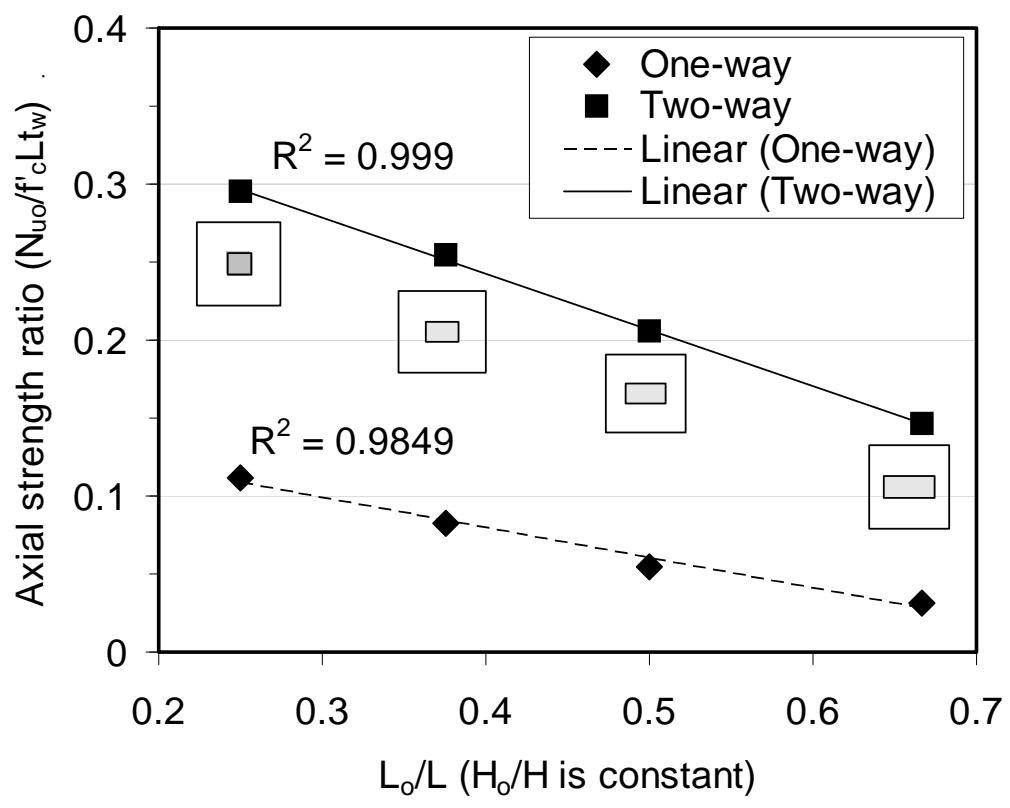

Figure 14 . Axial strength ratio vs $L_{o} / L$ 


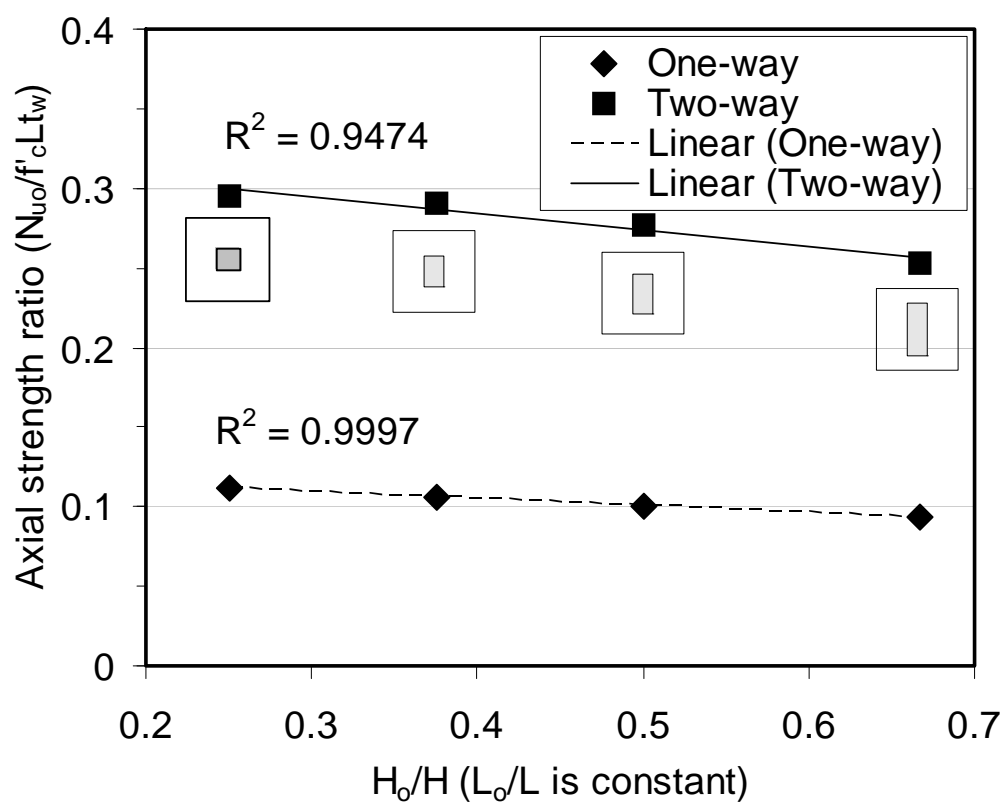

Figure 15. Axial strength ratio vs $H_{o} / H$ 


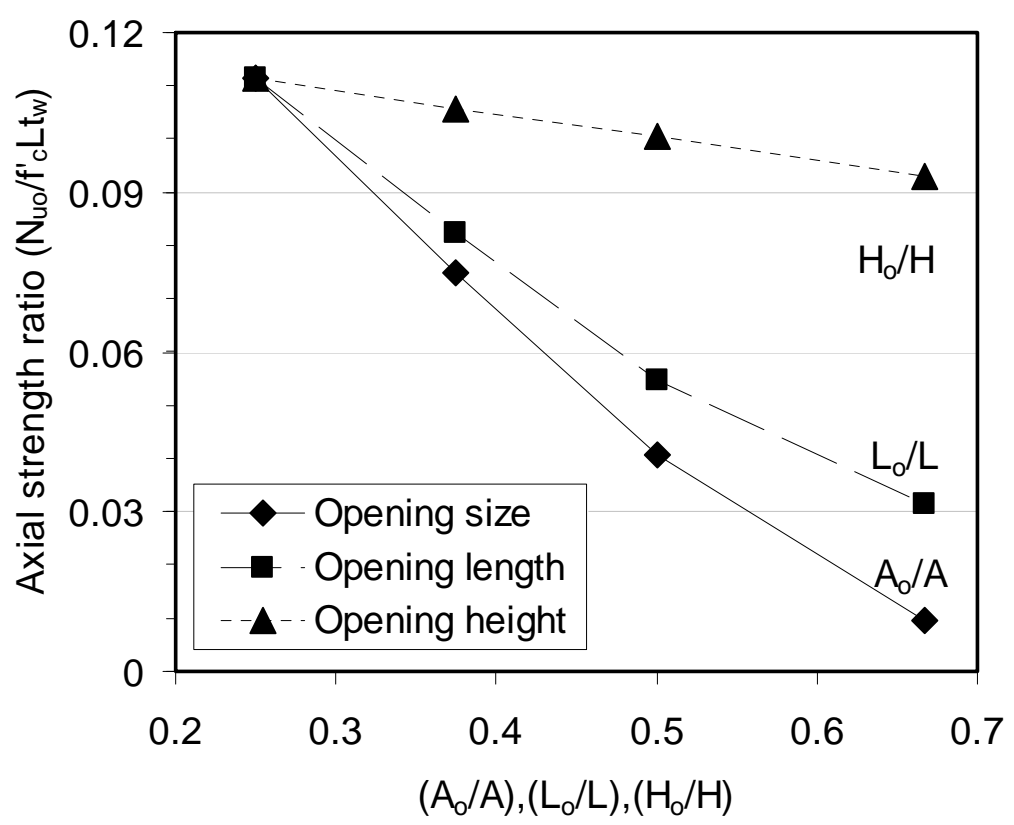

(a) One-way models

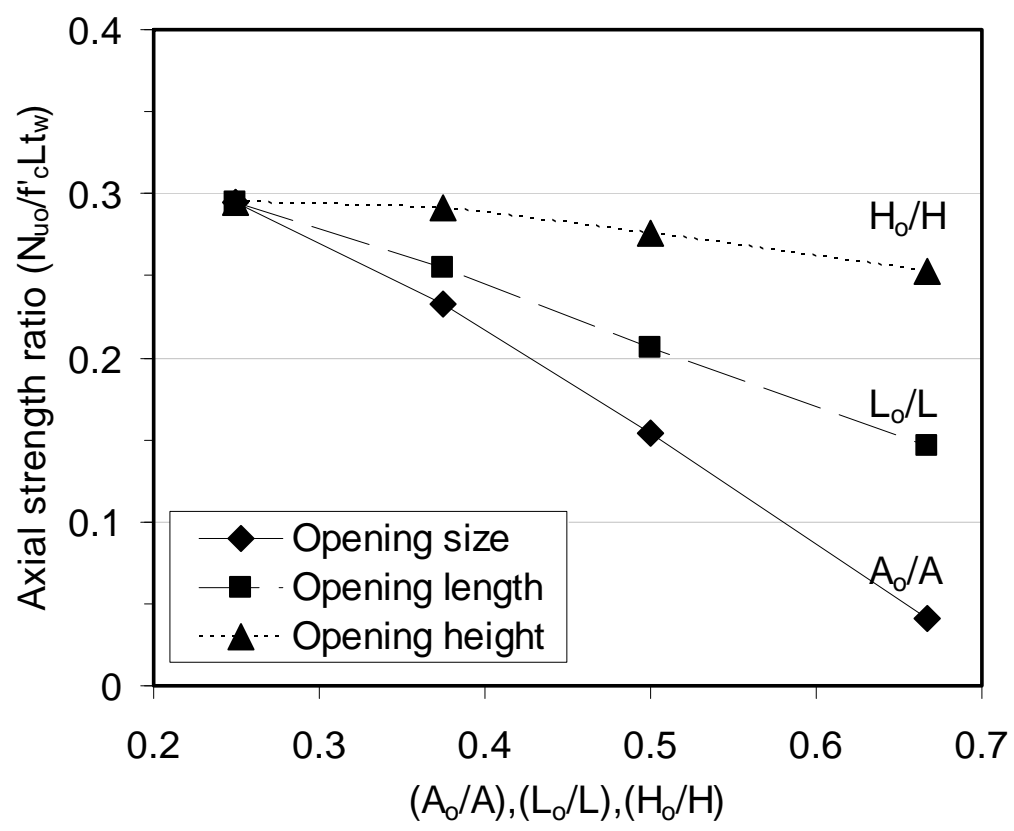

(b) Two-way models

Figure 16. Comparison of axial strength ratio for one-way and two-way models 


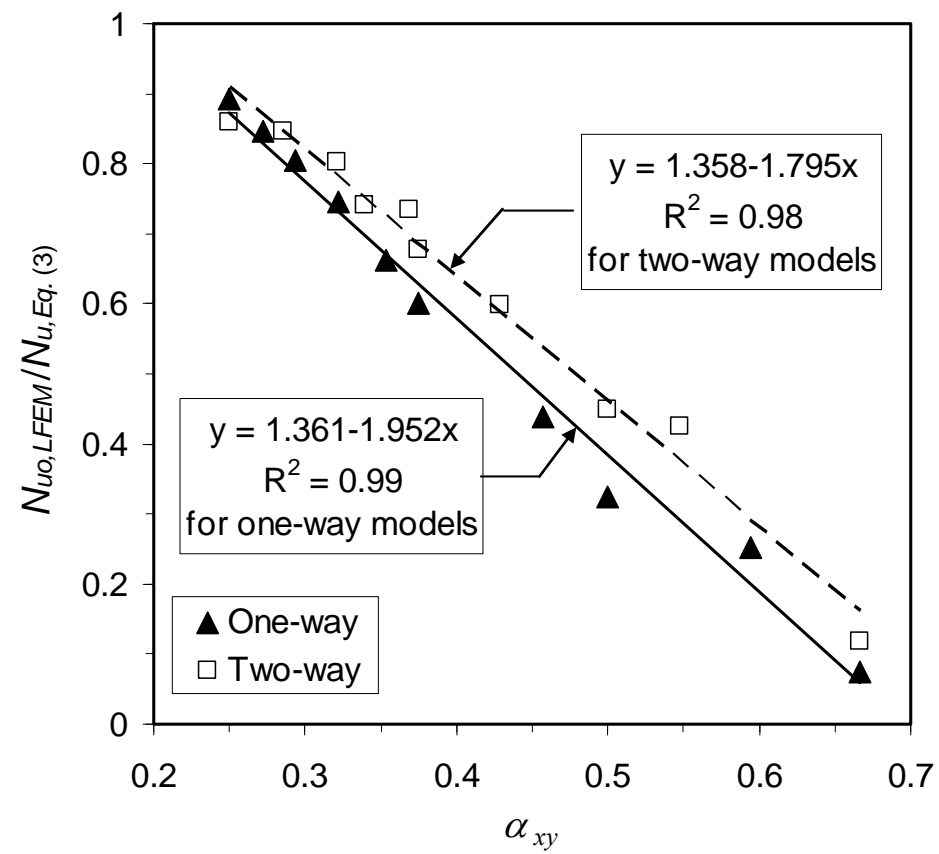

Figure 17. Regression analysis for one-way and two-way models 